\title{
Raising Revenues for Charity: Auctions versus Lotteries*
}

by

\author{
Douglas D. Davis ${ }^{+\wedge}$ Laura Razzolini, ${ }^{\#}$ Robert Reilly^and Bart J. Wilson ${ }^{\dagger}$
}

October 28, 2003

JEL Codes: C91, D44, D64,

Keywords: auctions, lotteries, charitable giving, experimental tests.

\footnotetext{
* We thank, without implicating, David Harless, Dan Houser, Mark Isaac and Kevin McCabe for their comments, as well as participants in an ICES Seminar at George Mason University and sessions at the 2002 Southern Economics Association Meetings in New Orleans LA and the 2003 Economic Science Association Meetings in Pittsburgh. Financial support from the National Science Foundation, the Virginia Commonwealth University Faculty Excellence Fund and the Robert M. Hearin Support Foundation are gratefully acknowledged. We also thank Jeffrey Kirchner for writing the software.

+ Corresponding author: dddavis@,vcu.edu, (804) 828-7140

^Department of Economics, School of Business, Virginia Commonwealth University, Richmond VA $23284-4000$

\# Department of Economics, University of Mississippi, Oxford MS 38677

$\dagger$ Interdisciplinary Center for Economic Science, 4400 University Drive, MSN 1B2, George Mason University, Fairfax VA 22030-4444
} 


\section{Raising Revenues for Charity: Auctions versus Lotteries}

Abstract: We report an experiment conducted to gain insight into factors that may affect revenues in English auctions and lotteries, two commonly used charity fund-raising formats. In particular, we examine how changes in the marginal per capita return (MPCR) from the public component of bidding, and how changes in the distribution of values affect the revenue properties of each format. Although we observe some predicted comparative static effects, the dominant result is that lottery revenues uniformly exceed English auction revenues. The similarity of lottery and English auction bids across sales formats appears to drive the excess lottery revenues. 


\section{Introduction}

Auctions and lotteries are standard means of raising funds for local public goods. Members of schools, churches, local sports clubs and community arts groups gather with frequency at fund-raising dinners and receptions to recognize their common interest in the charitable cause and the generosity (and in some cases the luck) of their fellows, some of whom win or purchase items that they value highly.

Beyond the utility of participating in such events, charity lotteries and auctions can also raise money effectively, and that aspect is the focus of this paper. Morgan (2000) analyzes the use of a lottery as a fund raising mechanism. Assuming homogeneous individual valuations for the prize, Morgan shows that when lottery ticket purchases reflect a combination of private values for the raffled item and some return from contributing to a charitable organization, a lottery may generate substantially higher revenues than would fund raising efforts through standard voluntary contributions. Intuitively, the chance of winning the raffled item mitigates the free-rider incentives that undermine fund raising through private voluntary contributions. Using experimental methods Morgan and Sefton (2000) generate empirical support for this prediction. Holding constant the rate of return that participants derive from public contributions (the $M P C R$ ), Morgan and Sefton observe markedly higher contributions in charity lotteries than in comparable voluntary contributions games, a difference that increases as participants become experienced with the mechanisms.

This paper extends the analysis of Morgan (2000) and Morgan and Sefton (2000) in two dimensions pertinent to many naturally occurring charity fund raising events. First, we allow for prize value heterogeneities. Significant value heterogeneities characterize many of the items typically offered for sale at charity events. At a local school auction, for example, differences in the perceived contribution of a particular son or daughter, sentimentality and aesthetic preferences may create very heterogeneous values among bidding parents for a collective class art project. ${ }^{1}$

\footnotetext{
${ }^{1}$ Value heterogeneities are not limited to local fund-raising events. For example, Engers and McManus (2001) discuss several charity auctions, such as the wine auctions hosted by Hospices de Beaune, the Napa Valley Wine Auctions, and an auction of guitars conducted in 1999 by musician Eric Clapton. More generally, items sold in charity fundraisers tend to be unique, nonstandard items for which a retail price is not well established. Other frequently auctioned items include dancers' shoes, the products of local artists and sporting memorabilia. (See, e.g., Wyman (1990) pp. 77-79). The possibility of a robust aftermarket may reduce the scope of value heterogeneities.
} 
Second, we consider the effects of altering the fund raising format. In natural contexts, the most standard selling formats at charity events include the lottery (or raffle) mentioned above, as well as an ascending price English auction. In the lottery, participants buy tickets, each potentially giving the holder the right to win a prize. At a pre-announced closing time, one of the tickets is drawn at random and the prize is awarded to the ticket-holder. The English auction sales format is sometimes conducted orally with an auctioneer, and sometimes conducted as a "silent auction." Oral auctions most typically follow standard English auction rules, with an auctioneer soliciting ascending bids until a single bidder remains, who purchases the item at his or her final bid price. In the silent auction bidders submit bids in writing for an item up to a preannounced closing time. During the silent auction, a recorder monitors bids privately as they are submitted, and displays continuously and publicly the highest bid. At the close of the auction, the highest bidder wins, and pays the bid price. ${ }^{2}$

Not only do the organizers or "hosts" of charity fund raising events vary these different selling formats across fund raising events, but hosts frequently vary selling formats across items at a single event. ${ }^{3}$ Participants may purchase lottery tickets for an automobile, or a vacation package, for example, and then bid in a silent auction for other items. We suspect that the issues of value heterogeneity and selling formats are interrelated. In particular, fund raisers may base their choice of selling format for an item on the kind of participants they expect may bid for the item, as well as the likely distribution of values among bidders.

Some theoretical studies have examined the effects of changing the sales format in charity events. However, the existing literature focuses on the relationship between sealed bid auctions and a variety of "all-pay" auctions where the high bidder wins the auction, but all bids are paid. Engers and McManus (2001) show that a first price all-pay auction generates higher revenues than a first price sealed bid auction. They further compare revenue predictions between

\footnotetext{
However, except for very big ticket items, transactions costs and financial constraints likely undermine the scope of after-markets frequently.

${ }^{2}$ As Isaac and Schneir (2003) observe, silent auctions also often involve the simultaneous sale of a variety of goods. These authors report that the simultaneous closing of bids for multiple items in silent auctions generates sizable revenue losses relative to auctions conducted one at a time. A tendency for participants to "guard" or monitor most closely the items that they value most highly dampens bidding activity.

${ }^{3}$ Indeed charity fund-raisers do not limit themselves to the auction and lottery formats described here. Interesting institutional fundraising variants include "Tumbola," a lottery where each ticket entitles the holder to a randomly selected prize, an "R-auction" where the auctioneer auctions off portions of a lottery wheel, and a "cent lottery" where participants purchase multiple ticket packets, which they split and place into jars aside multiple items that are raffled simultaneously. For a description of different fund-raising sales formats, see Nash (2000) or Wyman (1990).
} 
the all-pay auction and the second-price sealed bid auctions. (Predictions of the latter auction format are typically used to derive price and revenue predictions for English auctions. ${ }^{4}$ ) Although Engers and McManus are unable to order unambiguously the revenue predictions for the two formats, they show that with enough bidders, the all-pay format generates higher revenues than the sealed bid auction. Goeree and Turner (2001) generalize the analysis of charitable all-pay auctions. They show that winner-pay auctions are poor revenue raisers, because the value of the highest-valued bidder sets an upper bound on revenues. All-pay auctions can generate much higher revenues. In particular, any $k+l^{\text {th }}$ price all-pay auction generates higher revenues than any $k^{\text {th }}$ price all-pay auction. Further, given a constant MPCR " $h$ ", $k^{\text {th }}$ price all-pay auction revenues become infinite whenever $k \leq 1 / h$.

In addition to our focus on the lottery and English auction selling formats typical of naturally occurring charity fund raising events, we depart from the existing literature in that we assume public knowledge of value realizations. In part, we make this assumption for analytical simplicity. The publicity of value information simplifies particularly the analysis of the heterogeneous value lottery. However, a very practical concern also justifies our assumption of publicly known values. Although the "hosts" at local charity fund-raisers may not know the entire distribution of value draws for any auction the local charity may conduct, we doubt that the hosts view potential bidders as random draws from a distribution. In particular, they probably can distinguish the items likely to attract only one or only a very small number of highvalue bidders from those items with much more homogeneous valuations, and may attempt to adjust the sales format correspondingly. ${ }^{5}$

Our lottery predictions follow from Hillman and Riley (1989) and Fang (2002), who use a rent-seeking context to motivate an analysis of lotteries in the case of heterogeneous, but

\footnotetext{
${ }^{4}$ Engers and McManus are careful to observe that second price auction bid and revenue predictions match those of an English auction only for a special "button auction" variant of the English auction. In the button auction, bidders indicate initial interest in an item by depressing a button. Bidders release their buttons as an ascending bid clock raises bids above their reservation prices. The bid clock stops and the auction ends when only one bidder remains. In a context where bids have no charitable component, Isaac, Salmon and Zillante (2002) show that "jump-bidding" or the possibility of increasing bids by more than the minimum increment may cause divergence in revenue predictions between second price and English auctions.

${ }^{5}$ One of the author's personal experiences with a private school fundraising events supports this observation. In a private school in a small University town, auction organizers base the sales format decision for collective class projects at least partly on whether or not one of the students' parents in a class is a doctor.
} 
publicly known values. ${ }^{6}$ In this paper, we extend the analysis of heterogeneous, but publicly known values to the charity context and then we compare revenue predictions with the case of the known-values English auction. We find that revenue predictions are importantly affected by the marginal per capita return (MPCR) from the public good, and by the distribution of values among bidders. In particular, the English auction generates higher expected revenues than a lottery when the item for sale is sufficiently idiosyncratic (that is, only a very few bidders value the item highly), and when the return from the public good component is low (that is, the MPCR is low).

We proceed as follows. Section 2 develops bid and revenue predictions for the silent auction and for lotteries in the case of known but heterogeneous values. Section 3 presents the experimental design and Section 4 discusses the experimental results. A short Section 5 concludes.

\section{A Simple Model of Silent Auction and Charity Auction Bidding.}

In what follows we first develop bid and revenue predictions for the English auction, and then we consider equilibrium bid and revenue predictions for the lottery. ${ }^{7}$ We close with bid and revenue comparisons under the two institutions.

Consider a situation where $n$ agents, $i=1, \ldots, n$ compete for an indivisible object or prize. Each agent is endowed with a heterogeneous value for the item, $V_{i}>0$, which is common knowledge. Without loss of generality, we rank order the values so that $V_{1} \geq V_{2} \geq \ldots \geq V_{n}>0$. The proceeds from either sales format go toward a public good that benefits all agents equally. For simplicity assume that the marginal benefit from the public good, or the MPCR, is a constant equal to $h, 0<h<1$. That is, each bidder $i$ derives some positive utility $h$ from each dollar contributions to the public good.

\footnotetext{
${ }^{6}$ Fang shows that in the known but private value case, lotteries may have advantages over the all-pay auction formats. In particular, he shows that given sufficient value heterogeneity, the lottery can raise higher revenues (e.g., cause more complete dissipation) than an all-pay auction. Fang also shows that the "exclusion principle" shown to apply to all-pay auctions by Baye, Kovenock and de Vries (1994) does not extend to the lottery. These results are interesting in that they differ somewhat from some conjectures by Goeree and Turner (2002) about the relationship between lotteries and all-pay auctions in the case where values are not known. Goeree and Turner argue that an allpay auction is essentially an efficient variant of a lottery and that removing the uncertainty about the winner will increase bids.

7 Pooling the analysis of silent and oral versions of ascending bid auctions abstracts from some complications peculiar to the silent auction format. As noted by Isaac and Schneir (2002), multiple silent auctions tend to be conducted simultaneously. Also silent auctions typically have a fixed closing time, which may encourage deadline effects, such as pulling high bids at the last minute, or waiting until the last minute to submit bids. In our experimental implementation of the English auction we abstract from these problems by auctioning off only one items at a time, and by injecting a "soft" closing rule where we extend bidding with the submission of late bids.
} 
2.1 The English Auction with Known Values and Charitable Intentions. Assume that each bidder optimizes a simple quasi-linear utility function, $U_{i}=V_{i}+h b_{i}$. In an English auction, any bidder will remain in the bidding as long as the utility from winning the auction exceeds the utility from not winning. Consider the maximal bid for high-valued bidder 1 . If forced, bidder 1 will raise the bid to $V_{1}$ : dropping out at $b_{1}=V_{1}-\varepsilon$ leaves bidder 1 without winning the auction, and with a utility $U_{1}=h\left(V_{1}-\varepsilon\right)$ from contributions to the public good (by the auction winner). An abovevalue bid $b_{1}=V_{1}+\varepsilon$ lets bidder 1 win the auction, but at a loss: the bidder's net utility would be $U_{1}=h V_{1}+\varepsilon(h-1)$. Bidder 1 's utility increases by reducing his or her bid to $b_{1}=V_{1}$, generating utility $U_{1}=h V_{1}$.

Now consider the bid function for any bidder $j$ other than bidder 1 . Knowing that bidder 1 will remain in the auction until the bid equals $V_{1}$, bidder $j$ maximizes his or her return by bidding $b_{j}=V_{1}-\varepsilon$, to earn utility $U_{j}=h V_{1}$. Thus, the equilibrium winning bid and revenue become $V_{1}{ }^{8}$

The static feature of this game bears emphasis. In a repeated context the highest valued bidder 1 could impose losses on low value bidders who are submitting bids above their private values. Nevertheless, the effect of the charitable component on the equilibrium bid strategy in the English auction context merits emphasis. Given public values, a positive $M P C R(0<h<1)$ increases the equilibrium bid from $V_{2}$ to $V_{1}$. The prediction is independent of the magnitude of $h$, provided that $0<h<1$. Further, additional increases in the public return affect neither bids nor revenues. This result is our first conjecture:

Conjecture 1: Any positive MPCR $=h, 0<h<1$ shifts the bids and revenues for the public information English auction from $V_{2}$ to $V_{1}$. Any further increase to an $M P C R=h$, $>h$ affects neither bids nor revenues. 2.2 Lottery with Known Heterogeneous Values and Charitable Intentions. Unlike the English auction, lottery participants pay their bids regardless of whether they win the prize or not. Given heterogeneous values for the prize, a subset of $n$ potential bidders may find non-participation

\footnotetext{
${ }^{8}$ This result may be viewed as a special case of revenue predictions for the private value English auction. Goeree and Turner (2002) show that in the case of private values and a positive MPCR, English auction revenues are bound by the expected value of the first and second order statistics from the value distribution, given $n$ draws, $E\left(V_{2}^{n}\right)$ and $E\left(V_{l}^{n}\right)$. Engers and McManus (2001) also anticipate our result. "Note how different strategies in the button auction would be if all valuations were common knowledge. In this full information situation all bidders other than the one with the highest valuation would want to remain in the auction for as long as possible to inflate the payment that the winner makes to the charity. (p. 12)"
} 
optimal. Consider the bids of $m$ bidders $m \leq n$, each of whom find participation optimal. Each participant $i$ bids $b_{i}$, to maximize expected utility

$$
E\left(U_{i}\right)=\frac{b_{i}}{B(m)} V_{i}-b_{i}+h B(m), \quad b_{i} \geq 0
$$

where $B(m)$ represents the sum of bids by all $m$ agents, and $\frac{b_{i}}{B(m)}$ is the probability of winning the lottery. Optimizing (1) with respect to $b_{i}$ and taking as given the bids of all the other agents, yields the first order condition:

$$
\frac{V_{i}\left(B(m)-b_{i}\right)}{B(m)^{2}}+h=1, i=1, \ldots, m .
$$

Solving for the optimal bid

$$
b_{i}=B(m)-B(m)^{2}\left(\frac{1-h}{V_{i}}\right), i=1, \ldots, m .
$$

Summing over the $m$ bidders, (3) yields an expression for the sum of bids or the total contributions to the charity

$$
B(m)=\frac{m-1}{(1-h) \sum_{i=1}^{m} \frac{1}{V_{i}}} .
$$

Hillman and Riley (1989) characterize the Nash equilibrium for a lottery game with $n$ players, as the largest subset of bidders $2 \leq n * \leq n$, each of whom submit strictly positive bids, and zero bids for bidders $n^{*+1}$ to $n .^{9}$ This result extends in a straightforward way to the present case, since the addition of a linear public return from the lottery changes both individual values and $B(m)$ by a factor $1 /(1-h)$. Formally, define:

$$
\begin{aligned}
& k=\min \left\{m: v_{m+1} \leq(1-h) B(m), m=2, \ldots, n-1\right\} \\
& n^{*}=\min \{k, n\}
\end{aligned}
$$

Then, Nash equilibrium bids are

$$
\begin{aligned}
& b_{i}{ }^{*}=b_{i}\left(n^{*}\right), \text { for } i=1, \ldots, n^{*} \\
& b_{i}{ }^{*}=0, \text { for } i=n^{*}+1, \ldots, n .
\end{aligned}
$$

where $b_{i}\left(n^{*}\right)$ is defined in (3). Lottery revenues are given by $B\left(n^{*}\right)$ in (4).

\footnotetext{
9 In his Theorem 1, Hemming Fang (2002) establishes uniqueness of the equilibrium characterized by Hillman and Riley (1989). Fang's proof contains some errors. Using a different approach, Davis and Reilly (2003) establish the uniqueness result.
} 
Prior to comparing predicted revenues across different fund raising formats, one feature of the lottery with a public return component merits comment. Observe from (4) that the equilibrium revenue increases with $h$, the $M P C R$. This becomes our second conjecture:

Conjecture 2: Lottery revenues move directly with the MPCR.

2.3 Revenue Comparisons. The English auction yields higher equilibrium revenues than the lottery if $V_{1}>B\left(n^{*}\right)$ or

$$
V_{1}>\frac{n^{*}-1}{(1-h) \sum_{i=1}^{n^{*}} \frac{1}{V_{i}}}
$$

Rearranging terms yields $(1-h) V_{1}<\frac{n^{*}-1}{\sum_{i=2}^{n^{*}} \frac{1}{V_{i}}+\frac{1}{V_{1}}}$ or,

$$
1-h<\frac{n^{*}-1}{\sum_{i=2}^{n^{*}} \frac{V_{1}}{V_{i}}+1} .
$$

Notice that inequality (7) holds (and the English auction generates relatively more revenues than the lottery) (i) as $h$, the $M P C R$, becomes small, and (ii) as $V_{1}$ becomes large relative to the other value draws. We summarize these revenue comparison results as two final conjectures:

Conjecture 3: Given a positive MPCR, the ratio of lottery revenues to English auction revenues moves directly with the MPCR.

Conjecture 4: Given a positive MPCR, the ratio of Lottery revenues to English auction revenues moves inversely with the high value draw, $V_{1}$.

As a final comment prior to presenting the experimental design, observe that the revenue effects articulated in Conjectures 1 to 4 can be sizable if sellers play static Nash equilibrium strategies. Table 1 illustrates English auction and lottery revenue predictions in the case of four agents with $h=\{0,1 / 3,2 / 3\}$, and for three mean preserving value realizations, $L=\{500,500$, $500,500\}, M=\{650,500,425,425\}$ and $H=\{800,500,350,350\}$. Looking at the English auction revenue predictions shown in the left portion of Table 1, observe that raising $h$ above zero raises revenue predictions from $V_{2}$ to $V_{1}$, as stated in Conjecture 1. Under the $H$ set of value realizations, English auction revenues increase by $60 \%$ (from 500 to 800 ) as $h$ increases from 0 
to $1 / 3$. However the effect is confined to the first deviation of $h$ above zero. Doubling $h$ from $1 / 3$ to $2 / 3$ does not further affect English auction revenues.

The grid in the left panel of Table 1 lists lottery revenue predictions. As stated in Conjecture 2, lottery revenues move continuously with changes in $h$. Holding constant the value sets, lottery revenues increase roughly $50 \%$ as $h$ increases from 0 to $1 / 3$, and then roughly double as $h$ increases from $1 / 3$ to $2 / 3$.

Consider finally, the comparative revenue effects summarized in Conjectures 3 and 4 . Starting at the upper right corners of the English auction and Lottery grids in Table 1 observe that with the $L$ value set and $h=2 / 3$, predicted Lottery revenues more than double the predicted silent auction revenues (1125 cents vs. 500 cents). Moving down and to the left observe that these differences fall and then reverse. With the $H$ value set, and $h=0$, silent auction revenue predictions exceed lottery revenues by roughly 50\% (500 cents vs. 335 cents).

Examining predicted bids and earnings for the two sales formats lends insight into the factors driving the revenue predictions shown in Table 1. Consider first bid and earning predictions for the English auction, summarized in Table 2(a). For the $M$ and $H$ value sets, notice that raising $h$ above zero raises the bid from the second highest value $\left(V_{2}\right)$ to the highest value $\left(V_{l}\right)$. Notice also that as $h$ increases, predicted earnings shift from zero for all bidders (for the $L$ value set) or zero for all bidders but the high value bidder (for the $M$ and $H$ value sets) to positive and equal earnings for all bidders. Finally, given $h>0$, notice that increases in the $M P C R$ do not alter English auction bid predictions, but equilibrium payoffs for all bidders increase continuously. ${ }^{10}$

Table 2(b) summarizes bid and expected earnings predictions for the lotteries. Lottery bids are notably more heterogeneous than those predicted in the English auction. Lottery participants submit identical bids only with the $L$ (homogeneous) value set, and the high value bidder $\left(V_{l}\right)$ bids increasingly more relative to his or her rivals as the value heterogeneity increases. Interestingly, however, in the lottery, higher bids do not necessarily translate into higher expected earnings. Notice, for example, that with the $H$ and $M$ value sets and $h=2 / 3$, the

\footnotetext{
${ }^{10}$ In the public-value English auction with $h>0$, the winning bidder realizes no surplus from winning the item, and thus the equilibrium earnings reflect the social welfare of the winning bid. This welfare would be reduced if the auctioned item came at a cost to the charity.
} 
two low value bidders $\left(\mathrm{V}_{3}\right)$ actually enjoy higher expected earnings than the high value $\left(V_{1}\right)$ and medium value $\left(V_{2}\right)$ bidders. $^{11}$

\section{Experimental Design and Procedures.}

To evaluate the behavioral relevance of Conjectures 1 to 4 , we conduct the following experiment. The experiment consists of a series of thirty 24-period lottery and auction sessions. Our parameterization follows from the $M P C R$ values $\{0,1 / 3,2 / 3\}$ and the value sets $\{H, M$ and $L$ \} used to generate the predictions in Table 1. In each session, a constant group of four bidders places lottery or auction bids under each of the value set combinations listed in Table 1. To facilitate procedures and to give participants some familiarity with both the auction institution and the public return from bidding, we hold both the MPCR and the auction institution constant within sessions. Thus, given two auction institutions and three $M P C R$ values, the experiment consists of six treatment cells.

Our primary interest is in the explanatory power of static Nash equilibrium predictions, when value realizations are not repeated extensively. To this end, we rotate both value sets, and the assignment of values to participants across periods within each session. Given four bidders and three value sets, we can, in a 12 period rotation, induce the high value draw (and the second high value draw) on each bidder once for each value set. Our 24 period auction or lottery sequence consists of two realizations of this 12 period rotation. To facilitate across-session comparisons, we repeat the same sequence of value set and value assignments each session. Appendix Table A1 enumerates the sequence of value assignments.

3.1 Experimental Procedures: At the outset of each session, we randomly seat volunteers at visually isolated PCs, and an experiment monitor reads instructions aloud as participants follow along on a copy of their own. The instructions explain English auction or lottery bidding procedures, including how to submit and modify bids on their computer, the effects of the group investment, and the way earnings are calculated. To assist ticket purchase decisions in the lottery, participants are given a ticket calculator. With the calculator, participants can calculate

\footnotetext{
${ }^{11}$ With $h=2 / 3$, lottery participants uniformly enjoy $2 / 3$ of the sum of bids. Expected earnings for the $V_{1}$ and $V_{2}$ value bidders are lower because the expected value of the prize is less than their optimal bid. Despite relatively low expected earnings, the predictions shown in Table 2(b) represent an equilibrium. Bid reductions for the $V_{1}$ or $V_{2}$ value bidders would reduce expected earnings for these bidders.
} 
expected earnings per period given differing assumptions about their own ticket purchases and the sum of purchases by the other participants. ${ }^{12}$ After answering any questions, the session begins.

At the outset of each period, each participant is endowed with 800 laboratory cents, and the monitor announces and writes on a white board the value set for the period (the value assignments and individual bidders, however, are not linked). In the English auctions, participants have 40 seconds to submit a bid. To avoid deadline effects we implement a "softstop" termination rule. Any bid submitted in the final 15 seconds of an auction period automatically extends the period by an additional 15 seconds. In the lotteries participants have 90 seconds to purchase tickets. ${ }^{13}$ In either sales format participants could submit bids or make ticket purchases in amounts up to and including their initial 800 cent endowment for the period. At the close of each period, a winner is identified, and each bidder's endowment for the period is incremented by the private and public returns from the auction to determine period earnings. The computer program also maintains for each participant a running total of his or her cumulative earnings.

This process is repeated 24 times, using the value schedule in Table A1 (this table is not distributed to participants). After period 24 the session ends, a monitor privately pays each participant the sum of his or her salient earnings, plus a $\$ 5$ appearance fee, and then dismisses them. We convert lab dollars into cash at the pre-announced rate of 2000 Lab Cents for US\$1. ${ }^{14}$ Participants were 120 student volunteers, primarily undergraduates, from George Mason University during the Spring Semester, 2003. Earnings for 45-60 minute sessions ranged from $\$ 11.50$ to $\$ 29.75$, and averaged $\$ 18.75$ (including the $\$ 5$ appearance fee).

\section{Experimental Results}

4.1 Overview. The mean revenue paths shown in Figure 1 illustrate some of the primary experimental results. ${ }^{15}$ Most prominently, observe that independent of the MPCR condition,

\footnotetext{
${ }^{12}$ A calculator is unnecessary in the English auction, since participants see their potential public and private returns updated in real time, as they submit bids.

${ }^{13}$ The 90 second lottery period roughly equated the temporal length of the English auction and lottery periods.

${ }^{14}$ The conversion factor allows closer approximation of equilibrium bid predictions than would be possible with a penny grid in U.S. currency.

${ }_{15}$ In the panels of Figure 1 the sequence of realizations of each value set in a session comprise the horizontal scale. As Table A1 illustrates, our design rotates the different value sets in a roughly even order throughout the sessions. Thus, in each session participants face each value set eight times.
} 
lottery revenues (thin gray lines) exceed persistently both English auction revenue (thin black lines) and static Nash predicted lottery revenues (thick dashed gray lines). In contrast to the comparatively stable and near-Nash revenue outcomes in the English auctions, lottery revenue outcomes persistently exceed static Nash lottery predictions, often spectacularly, by margins of $200-300 \%$. Lottery revenues approach English auction revenues only in the latter periods of the $h=0$ treatments (when English auctions are predicted to raise substantially higher revenues). Lottery revenues in excess of Nash predictions have been observed previously in a charity lottery context $(h>0)$ with symmetrical bidders by Morgan and Sefton (2000), and in asymmetric rentseeking contexts (with $h=0$ ) by Davis and Reilly $(1998,2000)$. However, to the best of our knowledge, the immense surplus of lottery revenues over static Nash predictions observed here is unique. Apparently, the simultaneous presence of asymmetric bidders and a positive MPCR generates a strong interactive effect.

Although the scale of excess lottery revenues dominates other effects, notice also that in the latter portion of the sessions, some predicted comparative static effects emerge. Consider in particular the predicted and observed mean revenues for the English auctions, shown in the upper panels of Figure 2. Observed revenues fail to follow predictions in the first session halves. Nevertheless, revenues for the $H\left({ }^{\circ} \bullet\right), L\left({ }^{\prime} \times\right.$ ') and particularly the $M\left({ }^{\circ} \circ\right.$ ') value sets spread at least weakly in the predicted rank order in the second session halves. Mean predicted and observed lottery revenues, shown in the lower panels of Figure 2, illustrate the predicted MPCR effect. A weak relationship between lottery revenues and the $M P C R$ in the first half gathers considerable strength in the second half. ${ }^{16}$

4.2 Revenue Effects. To evaluate quantitatively these observations, as well to evaluate formally Conjectures 1 to 4 , we use a linear mixed-effects model to estimate revenues in the different sales format, value dispersion, and $M P C R$ conditions. Specifically, we estimate revenues in period $t$ of session $i\left(R_{i t}\right)$ as

\footnotetext{
${ }^{16}$ Comparing the upper and lower panels of Figure 2, notice that we double the vertical scale of the lotteries relative to the English auctions. The doubling of the scale facilitates our highlighting both the comparatively subtle effects of increasing value dispersion in the English auctions, and the much more pronounced relationship between lottery revenues and the MPCR. Notice also in the lower panel of Figure 2 that even in the latter session halves, lottery revenues fail to consistently move inversely to value heterogeneity, as predicted.
} 


$$
\begin{aligned}
R_{i t}= & \beta_{0}+\left[\beta_{e v} v_{t}+\beta_{e v^{H}} v_{t}^{H}+\beta_{e h} h_{i}+\beta_{e h^{2 / 3}} h_{i}^{2 / 3}\right. \\
& \left.+\beta_{e h v} h_{i} v_{t}+\beta_{e h v^{H}} h_{i} v_{t}^{H}+\beta_{e h^{2 / 3} v} h_{i}^{2 / 3} v_{t}+\beta_{e h^{2 / 3} v^{H}} h_{i}^{2 / 3} v_{t}^{H}\right] e_{i} \\
& +\left[\beta_{\ell}+\beta_{\ell v} v_{t}+\beta_{\ell v^{H}} v_{t}^{H}+\beta_{\ell h} h_{i}+\beta_{\ell h^{2 / 3}} h_{i}^{2 / 3}\right. \\
& \left.+\beta_{\ell h v} h_{i} v_{t}+\beta_{\ell h v^{H}} h_{i} v_{t}^{H}+\beta_{\ell h^{67} v} h_{i}^{67} v_{t}+\beta_{\ell h^{2 / 3} v^{H}} h_{i}^{2 / 3} v_{t}^{H}\right] \ell_{i} \\
& +\xi_{i}+\varepsilon_{i t} \\
i=1, \ldots, 30, t & =1, \ldots, 12,
\end{aligned}
$$

where the fixed effects are defined as follows:

$e_{i}=1$ if session $i$ was an English Auction.

$\ell_{i}=1$ if session $i$ was a Lottery.

$h_{i}=1$ if session $i$ used $h=.1 / 3$ or $2 / 3$.

$h_{i}^{2 / 3}=1$ if session $i$ used $h=2 / 3$.

$v_{t}=1$ if period $t$ used the $M$ or $H$ Value sets.

$v_{t}^{H}=1$ if period $t$ used the $H$ Value set.

To control for interdependencies within sessions we define sessions as panels, and then assume a random effects error structure within panels. Also, to control for serial correlation we assume a first order autoregressive process. Thus, the sessions in (8) are modeled as random effects $\xi_{i} \sim$ $N\left(0, \sigma_{\xi}^{2}\right)$. We also accommodate non-spherical disturbances by $\varepsilon_{i t}+\rho \varepsilon_{i t-1}+\eta_{i t},\left|\eta_{i t}\right|<1$ and $\eta_{i t} \sim N\left(0, \sigma^{2} \eta_{t}\right)$. Finally, to gain insight into temporal effects, we divide the data into two twelveperiod halves, and conduct separate regressions on each half. ${ }^{17}$

Despite its length, equation (8) is easy to follow. We model value set heterogeneity and MPCR interactions as marginal changes to a cumulative total, starting with $h=0$ and the $L$ value set in the English auction as the baseline revenue, $\beta_{o}$. The coefficients for each of the other 17 terms estimate the marginal revenue effects of treatment changes that deviate in progressive increments from the baseline condition. The first two rows consist of $M C P R$ and Value set interactions for the English auctions. The second two rows list a parallel set of interactions for the lotteries, as well as a lottery intercept term (when $h=0$ with the $L$ value set). Modeling interactions as in (8) generates non-arbitrary estimates of each of the 18 treatment cells as a unique set of parameters. Table 3 summarizes. Notice in particular the bolded entries in Table

\footnotetext{
${ }^{17}$ The xtregar procedure in the STATA statistical package generates the estimates reported in Table 4.
} 
3. These entries highlight the marginal effects that distinguish each treatment cell. Column (d) of Table 4 lists the predicted magnitude of these marginal effects given static Nash behavior.

Columns (b) and (c) of Table 4 report the estimates. In Table 4, as well as in the tables that follow, we evaluate both comparative static effects (e.g., coefficients that deviate from zero in the theoretically predicted direction) and conformance with equilibrium predictions. The entries in parenthesis below each parameter report the probability that an estimate deviates significantly from zero in the direction predicted by static Nash behavior. Bolded italicized and bolded upright entries highlight, respectively, instances where estimates deviate from zero at 90\% and 95\% confidence levels. Single and double asterisks printed aside entries indicate, respectively, $90 \%$ and $95 \%$ confidence levels that an estimate deviates from the predicted effect. $^{18}$

The results in Table 4 reflect clearly some of the observations made previously. Notice in particular the large and significant $\ell$ estimates, highlighted with a grayed box in row (1.1). These estimates are not bolded, as they deviate above, rather than below zero as predicted. However, as indicated by the asterisks, both the first-half estimate of 784.1 and the second-half estimate of 316.76 significantly and substantially exceed the static Nash prediction of -125 . Notice also the $\ell h$ and $\ell h^{2 / 3}$ coefficients, shown in rows (1.4) and (1.5) of Table 4. These coefficients estimate the marginal effects of $M P C R$ increases in lotteries. In the first session half $\ell h$ and $\ell h^{2 / 3}$ are relatively small and differ insignificantly from zero. However, in the second session halves $\ell h=480.35$ and $\ell h^{2 / 3}=408.93$, and both significantly exceed zero, as predicted, suggesting that with some repetition lottery revenues become sensitive to the MPCR.

The marginal results in Table 4, however, reflect other observations incompletely. Notice in particular the $e h v$ and $e h v^{H}$ parameters reported in rows (0.6) and (0.7) of Table 4. These parameters estimate the marginal effects of increases in $V_{l}$, the maximal value draw, on English auction revenues. In contrast to predictions, the $e h v$ and $e h v^{H}$ parameter estimates not only fall below their predicted values of 150 , but also the estimates do not differ significantly from zero in either the first or the second session halves. The insignificance of the these estimates stands in apparent contrast to the mean revenue results for the second session halves shown in the upper right portion of Figure 2, particularly when $h=1 / 3$. Unanticipated

\footnotetext{
${ }^{18}$ Thus, the probabilities reported below the estimates reflect results of one-tailed tests, while the asterisks reporting the significance of deviations from Nash predictions reflect results of two tailed tests
} 
interaction effects disguise the effects illustrated in Figure 2. The ehv and $e h v^{H}$ coefficients estimate only the cumulative marginal effects of increasing both value set heterogeneity and the MPCR (from $h=0$ to $h=1 / 3$ ). Estimating the effect of value heterogeneity increases when $h=$ .33 requires evaluation of the sums $e v+e h v$ and $e v^{H}+e h v^{H}$. As is evident from the $e v$ and $e v^{H}$ estimates shown in rows (0.2) and (0.3) of Table 4 these latter terms, which reflect some tendency for subjects to bid above Nash predictions when $h=0$, become relatively large quantitatively (albeit insignificant individually) in the second session halves.

In fact, unanticipated interaction effects generally undermine a comprehensive evaluation of treatment effects from results reported in Table 4. The lottery estimates contain some particularly notable examples. Consider the parameters $\ell h v$, and $\ell h v^{H}$, shown in rows (1.6) and (1.7) of Table 4. In the second session halves these parameters take on values of -287.68 and 252.35 respectively, far different from their predicted levels of -6 and -15 . To evaluate the robustness of sales format, value set and $M P C R$ treatment effects, we must account for the impacts of these unpredicted interaction effects. Below we draw formal conclusions about experimental results that account for interaction effects by evaluating observed outcomes in light of predicted changes in the parameter combinations shown in Table $3 .{ }^{19}$

Consider first the effects of switching the sales format from an English auction to a lottery. Establishing the robustness of the tendency for lottery revenues to exceed English auction revenues requires comparison of each lottery parameter combination shown in the lower portion of Table 3 with its English auction counterpart, shown in the upper portion of Table 3. Table 5(a) summarizes the predicted effects. The left panel of Table 5(a) lists the resulting parameter differences, and the right panel of Table 5(a) prints the predicted values of these combinations, given static Nash equilibrium bidding. Notice in the right panel of Table 5(a) that lottery revenues are certainly not predicted to exceed consistently English auction revenues. Indeed, five of the nine predicted differences are negative, and some of the differences are quantitatively quite large (the $h v^{H}$ prediction, for example, is -298 cents).

In an analysis comprised entirely of indicator variables, we can evaluate the significance of parameter restrictions by constructing new indicator variables as the sum of the indicator values for each of the combined parameters. The estimated parameter value for the combined

\footnotetext{
19 The problem of accounting for interaction effects arises frequently in the analysis of experimental data. We offer the rather lengthy analysis of the problem here as a suggested general approach.
} 
variable recovers an estimate of the sum of the predicted parameter combinations shown in the left side of Table 5(a). Table 5(b), which uses the same reporting format used in Table 4, summarizes the relevant estimates. ${ }^{20}$ As is evident from the asterisks in each entry, the difference between Lottery and English auction revenues uniformly exceeds the predicted differences both in the first and in the second session halves. Further, notice that lottery revenues uniformly exceed English auction revenues, often by quantitatively very large amounts. The dominance of lotteries over English auctions as a revenue-raising mechanism represents our first finding.

Finding 1: Lottery revenues persistently exceed English auction revenues. This result is robust to repetition, the MPCR level and the value set used.

We turn now to the theoretical revenue predictions stated as Conjectures 1 to 4 . Conjecture 1 is a comparative static claim about English auctions. Specifically, given a positive $M P C R$, conjecture 1 posits that English auction revenues increase with $V_{1}$, the highest induced value. To evaluate this conjecture we restrict attention to the six English auctions treatment cells where $h>0$ (e.g., the columns $h=1 / 3$ and $h=2 / 3$ in the upper portion of Table 3 ). To calculate the predicted equilibrium differences associated with changing the value set, difference the entries within each column (MPCR level) across rows (value sets). The left and right panels of Table 6(a) illustrate, respectively, the resulting relevant parameter combinations, and the predicted combination values. Notice the predicted value of 150 in each cell in the right panel of Table 6(a). These predictions reflect the predicted effects on total revenue of increasing $V_{1}$ (from 500 to 650 , or from 650 to 800 ) when $h=1 / 3$ (the left-hand column) and when $h=2 / 3$ (the righthand column).

Table 6(b) summarizes estimates of value set changes on English auction revenues. In the first session half, summarized in the left panel of Table 6(b), observe that value set changes do not affect English auction revenues significantly. However, turning to the panel on the right side, notice that with repetition bids spread consistently in the predicted direction, and that the differences are significant (at a $90 \%$ confidence level) when $h=1 / 3$. Importantly, the way that $V_{1}$ increments affect English auction revenues is not entirely consistent with the underlying theory. As mentioned in the introduction to this analysis, participants show some tendency to

\footnotetext{
${ }^{20}$ The standard errors of estimates for the combined parameters provide the basis for the statistical comparisons made in Table 5(b).
} 
bid above the predicted second highest value when $h=0$. Notice further, in the right panel of Table 6(b) that value set changes fail to increase English auction revenues significantly when $h=$ $2 / 3$. We have no definitive explanation as to why the effects of $V_{1}$ increases appear to diminish as the MPCR increases from $h=1 / 3$ to $h=2 / 3$, and offer this result as a curiosity for further investigation. $^{21}$ In any case, we summarize the limited effects of value set increases on English auction revenues form a second finding.

Finding 2: With repetition, and with $h=1 / 3$ revenues in full-information English auctions move directly with the highest induced value. However, the effect is weaker than predicted, and in any case revenue-enhancing effects of increasing the highest induced value no longer remains significant when $h=2 / 3$.

Consider next the lotteries. Conjecture 2 stipulates that lottery revenues move directly with the MPCR. To evaluate this conjecture, we find, for each Value set, the lottery parameter combinations in Table 3 that survive changes in the MPCR, (e.g., difference the row entries in the lower portion of Table 3 across columns). The left and right panels of Table 7(a) illustrate, respectively, parameter combinations and their predicted values. Notice in the right panel of Table 7(a) that MPCR increases affect predicted revenues convexly: for each value set, the effect of increasing $h$ from $1 / 3$ to $2 / 3$ more than doubles the effects of increasing $h$ from 0 to $1 / 3$.

The observed effects of MPCR increases in lotteries, printed in Table 7(b) suggest that lottery participants respond to $M P C R$ increases, and that the effect becomes more pronounced with repetition. As seen in the left panel of Table 7(b), in the first session half, the relationship between MPCR changes and lottery revenues follows predictions imprecisely: increasing $h$ from 0 to $1 / 3$ raises revenues in all value sets, and significantly so for the $M$ and $H$ sets. However, further increasing $h$ from $1 / 3$ to $2 / 3$ exerts no significant additional effect for inexperienced participants, despite a considerably larger predicted effect. In the second session halves, summarized on the right side of Table 7(b) lottery revenues still increase by more than the

\footnotetext{
${ }^{21}$ One possibility is that participants attend more closely to the relative earnings effects of a bidding decision than to the absolute earnings effects. Although the absolute earnings consequences of raising a bid are independent of the $M P C R$, the percentage earnings increments fall with MPCR increases. To see this, consider the earnings consequences of a bid of 600 for the high value bidder when $V_{l}=800$. When $h=1 / 3$, the $V_{l}$ bidder earns $(800-600)$ $+.33(600)=400$ from winning the auction, and $.33(600)=200$ from losing. When $h=2 / 3$, the $V_{l}$ bidder earns $(800$ $-600)+.67(600)=600$ from winning the auction, and $.67(600)=400$ from losing. Although the earnings difference between winning and losing is 200 in either condition, the change represents a $50 \%$ increase over the return from losing when $h=1 / 3$, but only a $33 \%$ increase in earnings when $h=2 / 3$. Indeed, the very high relative increase in earnings may explain why high value bidders respond to bids above 500, despite the fact that such bids leave lower valued rivals exposed to losses. When $h=0$, the $V_{l}$ bidder earns $(800-600)+200=400$ from winning the auction, and .200 from losing, a 100\% increase.
} 
predicted amount for the increase in $h$ from 0 to $1 / 3$. However, with repetition, the lotteries exhibit an increased sensitivity to the adjustment in $h$ from $1 / 3$ to $2 / 3$. Further, all the lottery revenue adjustments in the second half revenues significantly exceed zero, except for increasing $h$ from 0 to $1 / 3$ with the $M$ value set. In this case, the observed revenue increase of 192.67 nearly matches the predicted increase of 182. However, sampling variability renders this difference insignificant. We summarize these observations as a third finding.

Finding 3. Lottery revenues tend to move directly with the MPCR. The effects of MPCR changes on revenues increase with repetition.

Conjectures 3 and 4 evaluate the relative revenue effects of $M P C R$ and value set changes in Lotteries and English auctions. Conjecture 3 posits that given a positive $M P C R$, the ratio of Lottery revenues to English auction revenues moves directly with the MPCR. Lottery and English auction revenue changes associated with the $M P C R$ increases provide relevant evidence to evaluate this conjecture: Conjecture 3 receives support to the extent that Lottery revenues increase more with a change in the MPCR than English auction revenues over the relevant range. In terms of the parameter combinations listed in Table 3, we evaluate whether the lottery parameter combinations that survive subtracting row entries across the columns $h=1 / 3$ and $h=$ 2/3 significantly exceed the comparable English auction parameter combinations. The left and right panels of Table 8(a) summarize, respectively the relevant combinations, as well as the differences predicted from equilibrium behavior. ${ }^{22}$

The observed relative effects of $M P C R$ increases, summarized in Table 8(b), suggest that the predicted effects of increasing the $M P C R$ emerge, but only with repetition. In the first session half, $M P C R$ increases stimulated only relatively small and insignificant increases in lottery revenues over English auction revenues. But with repetition, $M P C R$ increases stimulated both substantially and significantly more lottery revenues than English auction revenues. In each value set lottery revenues increased at least 395 cents more than English auction revenues, and the differences all exceed zero at a minimum $90 \%$ confidence level. These observations form our fourth finding.

Finding 4: With $h>0$ the ratio of lottery revenues relative to English auction revenues moves directly with the MPCR.

\footnotetext{
${ }^{22}$ Notice in the right side of Table 8(a) that the predicted differences equal the marginal effect of increasing $h$ on lottery revenues, shown, for example, in the right side of Table 7(a). Recall that given $h>0$, additional $h$ increases do not affect predicted English auction revenues.
} 
Conjecture 4 evaluates the relative effects of value heterogeneity changes on the two sales formats. Specifically the conjecture posits that given $h>0$, the ratio of lottery revenues to English auction revenues moves inversely with value dispersion. Evidence supports conjecture 4 to the extent that English auction revenues increase more (or decrease less) than comparable Lottery revenues when the high value, $V_{1}$, increases. In terms of the parameter combinations shown in Table 3, we evaluate whether the English auction parameter combinations that survive differing relevant column entries $\left(h=1 / 3\right.$ and $h^{2 / 3}=2 / 3$ ) across rows (e.g, $v$ less $\sim v$, and $v^{H}$ less v) significantly exceed the comparable parameter combinations in lotteries. As was the case for the other conjectures, Table 9(a) summarizes relevant parameter combinations and the predicted differences.

Observed differences, summarized in Table 9(b) provide equivocal support for Conjecture 4. Notice in the for the first session half, shown in the left panel of Table 9(b), that lottery revenues actually respond more than English auction revenues to the change from the $L$ value set to the $M$ value set (as indicated by the negative entries in the upper row). However, for the change from the $M$ to the $H$ value set English auction revenues increase significantly more than Lottery revenues, as predicted, and the effect is significantly different from zero at a $95 \%$ confidence level when $h=1 / 3$. However, the effects of increasing $V_{1}$ do not cleanly extend with repetition. The relative effects of changing from the $L$ to the $M$ value set become positive in the second session half (and significantly so when $h=1 / 3$ ). However, repetition appears to diminish the effects of changing from the $M$ to the $H$ value set. These inconclusive results form a fifth finding.

Finding 5: The ratio of lottery revenues to English auction revenues do not consistently move inversely with increases in $V_{1}$.

4.3 Bidding. Although we framed our theoretical analysis largely in terms of revenue effects, a consideration of bidding behavior provides some insight into experimental results. The predicted and observed mean closing English auction bids and mean lottery bids, shown in Figure 3, suggest two features of bidding that drive much of the results summarized in Findings 1 to $5 .^{23}$ First, neither closing English auction bids ('•’) nor Lottery bids (' $\circ$ ’) track underlying English

\footnotetext{
23 "Closing bids" in the English auctions are the final bids submitted in a period by participants with a particular
} value draw. Mean closing bids are closing bids averaged across period segments, and bidders with the value draw. 
auction predictions ('-+-') or Lottery predictions ('---') particularly well. In the English auctions, bids tend to move with underlying values, contrary to predicted behavior in this full information game, and the effect does not appear to dissipate with repetition. In the lotteries, all bidders persistently exceed static Nash lottery predictions. Comparing lottery bids across the left and right columns of Figure 3, notice that unlike the English auctions, lottery bids show some tendency to decay in the direction of Nash predictions with repetition, as can be seen from comparing lottery bids across the left and right columns of the figure. Nevertheless, even with repetition, overbidding persists in the lotteries.

Second, notice the similarity of closing English auction and lottery bids, particularly in the first session halves, summarized in the left panels. With repetition, the difference between closing English auction and lottery bids increases, as lottery participants adjust their bids downward. However, the similarity of bids across sales formats in the first portion of sessions suggests why lottery revenues so spectacularly exceed English auction revenues. At least in this four-bidder context, bids are similar across sales formats. The similarity of lottery and English auction bids results in increased lottery revenues, because unlike the English auction, all lottery bids are paid.

To provide the quantitative support for the above observations regarding bidding behavior, we again use a linear mixed effects model to estimate differences in closing English auction and lottery bids. Following the convention for identifying bid predictions used in Tables 2(a) and 2(b), label the high, medium and low induced values as $V_{1}, V_{2}$ and $V_{3}$, respectively. Then, for each MPCR level $(h=0,1 / 3,2 / 3)$ we estimate the bid by participant $i$ in period $t\left(B_{i d}\right)$ as.

$$
\begin{aligned}
\text { Bid }_{i t} & =\beta_{o}+\beta_{v^{2} \ell} v_{t}^{2} \ell_{i}+\left(\beta_{v^{1}}+\beta_{v^{1} \ell_{i}} \ell_{i}\right) v_{t}^{1} \\
& +\left(\beta_{v^{3}}+\beta_{v^{3} \ell} \ell_{i}\right) v_{t}^{3}+\xi_{i}+\varepsilon_{i t} \\
& i=1, \ldots, 40, t=1, \ldots, 4, \text { or } 5, \ldots, 8
\end{aligned}
$$

where

$\ell_{i}=1$ if participant $i$ was in a Lottery session.

$v_{t}^{1}=1$ if participant $i$ 's value draw in period $t$ was 800 in the $H$ set, or 650 in the $M$ set

$v_{t}^{2}=1$ if participant $i$ 's value draw in period $t$ was 500 .

$v_{t}^{3}=1$ if participant $i$ 's value draw in period $t$ was 350 in the $H$ value set or 425 in the $M$ value set. 
We estimate bids in the $H, M$ and $L$ value sets separately. ${ }^{24}$ Also, as with (8) we control for interdependencies within sessions, this time by defining individuals as panels, and then assume a random effects error structure within panels. Also, to control for serial correlation we assume a first order autoregressive process. Thus, in (9) $\xi_{i} \sim N\left(0, \sigma^{2}\right), \varepsilon_{i t}+\rho_{e_{i t-1}}+\eta_{i t},\left|\eta_{i t}\right|<1$ and $\eta_{i t} \sim N\left(0, \sigma^{2} \eta_{t}\right)$. Finally, to allow for insight into temporal effects, we divide the data into two twelve period halves, and conduct separate regressions on each half.

The structure of equation (9) merits comment. Using closing English auction bids for the bidder(s) with a value of 500 as the intercept, we estimate the marginal effects of each of the other realizations in the value set as well as the incremental effects of switching the sales format to a lottery at each value set. To the extent that bids move with underlying values, the $V_{1}$ parameters ( 800 or 650$)$ will be positive and the $V_{3}$ parameters $(350$ or 425$)$ will be negative. To the extent lottery and English auction bids track each other, lottery bid estimates (e.g,. those appended with an $\ell$ ) will parallel comparable English auction estimates.

Regression results, printed in Tables 10(a), 10(b) and 10(c) illustrate both the persistent tendency for closing bids to follow values in the English auctions, and for English auction and Lottery bids to track each other. Consider first the correlation between closing bids and values in the English auctions. The shaded portions of Table 10(a) and 10(b) highlight the relevant evidence. Were bids and underlying values uncorrelated (as predicted in the English auction) the coefficients on value deviations from 500 would differ insignificantly from zero. Scanning down the shaded portion in left column of Tables 10(a) and 10(b), notice that in the first session halves, the null hypothesis is rejected at a minimum $90 \%$ confidence level in 7 of the 12 comparisons. Nor does the tendency for English auction bids to track underlying values diminish with repetition. To the contrary, as shown in the shaded boxes on the right side of Tables 10(a) and 10(b), the null hypothesis that bids are insensitive to value deviations is rejected in 10 of the 12 comparisons.

The hollow boxes in Tables 10(a) to 10(c) provide evidence pertinent to the correlation between closing English auction and lottery bids. If sellers follow static Nash bidding strategies, for every combination of MPCR and values, lottery bids should be much lower than closing English auction bids. However scanning down the hollow boxes on left side of Tables 10(a) to 10(c) observe that in the session halves, closing English auction bids and lottery bids are more

\footnotetext{
${ }^{24}$ Since values are homogenous, the regression for the $L$ value set estimates only first two parameters in (9).
} 
similar than they are different. We can reject the null hypothesis that lottery bids are not less than English auction bids at a minimum 90\% confidence level in only 5 of the 21 combinations of MPCR and value. With repetition, lottery and English auction bids separate to some extent. Nevertheless, separation remains incomplete. As summarized in the hollow boxes shown in the right side of Tables 10(a) to 10(c), lottery bids are significantly below English auction bids in 10 of the 21 combinations of MPCR and value. We summarize these observations as a final, sixth finding.

Finding 6. The similarity of bids across sales formats drives the observed excessive lottery revenues. Contrary to predictions, closing bids in our full information English auctions move with underlying values. Lottery bids track closing English auction bids closely, despite the fact that lottery bids are paid whether or not bidder wins the auction.

\section{Closing Comments.}

Given the choice between lottery and English auction sales formats to raise charitable funds, our experimental results suggest that lotteries are clearly the preferred sales format. Lottery revenues uniformly dominate English auction revenues. Further, an analysis of bids indicates that a failure of participants to adjust their bids for changes in the sales format drives the excess lottery revenues.

Viewed in light of our results, the persistence of the English auction as a preferred fundraising sales format prompts some reflection on the relationship between our experimental environment and naturally occurring charity events. Two potentially important differences come to mind. First, naturally occurring charity raffles often have a large number of participants. As the number of bidders becomes large, participants may come to adjust their bid for the sales format. ${ }^{25}$ Second, in a fundraising context, bidders in oral English auctions may derive some considerable utility from demonstrating publicly their largess, and their determination to do whatever necessary to take home an item coveted by group members. ${ }^{26}$ In future research we plan to evaluate these and other related issues. ${ }^{27}$

\footnotetext{
${ }^{25}$ Casual observation suggests that some adjustment must place. Churches and school raffles for big ticket items, such as automobiles often include revenue caps, whereby total ticket sales are limited to a pre-announced fixed number. Presumably such commitments would be unnecessary if bidders did not adjust ticket purchases for lottery sales format. On the other hand, if overbidding in lotteries persists when the number of bidders is small, a charity sales format that sharply restricted the number of bidders might actually result in increased revenues.

${ }^{26}$ In their analysis of some naturally occurring charity auctions, Isaac and Schnier (2003) report some evidence of what they call "see and be seen" preferences as an explainer of jump-bidding activity in silent Charity auctions.
} 
Issues other than the bidding environment may also explain the persistence of English auctions as a fund-raising sales format. Importantly, lotteries and raffles are not always possible. Some religious organizations proscribe the use of lotteries or raffles as a type of gambling. ${ }^{28}$ Further, regulations regarding lotteries vary substantially across states and countries, and in many instances charity lotteries are effectively illegal. ${ }^{29}$ Aside from legal restrictions, evidence from the fund raising trade literature suggests that the silent auction variant of the English auction is widely viewed as a pleasant, non-threatening event that provides the "social-glue" that allows fund-raising effects to occur in the first place. The silent auction format creates a social context that draws in participants, and creates an audience for the high-revenue items, which may be raffled off, or sold at live auction. To the extent that this latter explanation drives the survival of auctions as a sales format, our comparative static results suggest when the silent auctions may be least costly: Lottery revenues are highly sensitive to the $M P C R$, and at least guarded evidence suggests that English auction revenues increase with value heterogeneity. Thus fundraisers may do well to use the silent auction format for items valued highly by particular individuals, perhaps at the beginning of an evening, when the case for the Charity has yet to be made. To the extent charitable intentions increase (and sobriety falls) as an event progresses, our results suggest that fundraisers may then find it wise raffle off big-ticket items toward the end of the evening.

Curiously, such preferences appear to be sensitive to the charity. More aggressive bidding was observed in an auction held for a private preparatory school than was observed in a pair of church auctions.

${ }^{27}$ Relaxing our assumption that bidders have full information about the value draws represents an additional dimension of our experimental design that merits further investigation. However, although suppressing information about value draws may reduce English auction bids somewhat, we are skeptical that information about value draws drives the excessive lottery revenues. Looking at the mean revenues show in Figure 2, for example, notice that lottery revenues do not appear to be importantly affected by value set changes.

${ }^{28}$ The Baptist and United Methodist Churches appear to be the most uniform in their opposition to lotteries. For explicit statements, see, for example, the United Methodist News Service Backgrounder on Gambling (revised 10/02) http://umns.umc.org/backgrounders/gambling.html, or Dr. Ray Prichart, Calvary Memorial Church: Gambling and the Christian Faith, (1991, Keep Believing Ministries).

http://www.cmcop.org/sermons/htm/issues/910725.htm

${ }^{29}$ For example, attorney Jed R. Mandel, advises fundraisers that most states proscribe as illegal gambling lotteries that are not run by the state. Certain states and locals allow exceptions for not-for-profit organizations, and in other instances charitable organizations can often circumvent state restrictions by structuring their lottery appropriately. However, Mr. Mandel advises charitable organizations to get legal counsel prior to conducting a charity lottery. See Primedia Business Magazines and Media, Association Meetings (Feb. 1, 2003.) www.MeetingsNet.com. 


\section{References}

Baye, M., Kovenock, D and De Vries C.G. (1994). "The Solution to the Tullock Rent-Seeking Game when R>2: Mixed Strategy Equilibria and Mean Dissipation Rates," Public Choice, 81, 363-380.

Davis, Douglas D. and Robert J. Reilly (2000). "Multiple Buyers, Rent-Defending and the Observed Social Costs of Monopoly," Pacific Economic Review 5, 389-410.

Davis, Douglas D. and Robert J. Reilly (1998). "Do Too Many Cooks Always Spoil the Stew? An Experimental Analysis of Rent-Seeking and the Role of a Strategic Buyer," Public Choice, 95, 89-115.

Davis, Douglas D. and Robert J. Reilly (2003) "Lotteries with Heterogeneous Values Revisited" Manuscript, Virginia Commonwealth University.

Fang, Hamming (2002). "Lottery versus All-Pay Auction Models of Lobbying," Public Choice, $112,351-371$.

Engers, Maxim and Brian McManus (2002). "Charity Auctions," Manuscript, Washington University, St. Louis.

Goeree, Jacob and John L. Turner (2002). "How (Not) to Raise Money,” Manuscript, University of Virginia.

Hillman, Arye and John G. Riley (1989) Politically contestable Rents and Transfers" Economics and Politics, 1, 17-39.

Isaac, R. Mark, Timothy C. Salmon and Arthur Zillante (2002). "A Theory of Jump Bidding in Ascending Auctions," Manuscript, Florida State University.

Isaac, R. Mark and Kurt Schnier (2003). "Run Silent, Run Cheap? A Study of a Charity Auction Mechanism," Manuscript, Florida State University.

Mandel, Jed (2003). "Primedia Business Magazines and Media Association Meetings," www.MeetingsNet.com.

Morgan, John (2000). "Financing Public Goods by Means of Lotteries," Review of Economics Studies, 67, 761-784.

Morgan, John and Martin Sefton (2000). "Funding Public Goods with Lotteries: Experimental Evidence," Review of Economic Studies, 67, 785-810.

Nash, David (2000). www.fetesandfestivals.com.au/contactus.htm.

Prichart, Ray, (1991). "Gambling and the Christian Faith," Keep Believing Ministries, http://www.cmcop.org/sermons/htm/issues/910725.htm 
United Methodist News Service Backgrounder on Gambling (2002). http://umns.umc.org/backgrounders/gambling.html.

Wyman, Ken (1990). Guide to Special Events Fundraising, VOLUNTARY Action program of Canadian Heritage $2^{\text {nd }}$ ed., www.pch.gc.ca/cp-pc/ComPartnE/pub list.htm. 
Table 1. Predicted Revenue Comparisons: English Auction and Lottery (in cents)

\begin{tabular}{|c|c|c|c|c|c|c|}
\hline \multirow[t]{2}{*}{$\underline{\text { Value Set }}$} & \multicolumn{3}{|c|}{ English Auction } & \multicolumn{3}{|c|}{ Lottery } \\
\hline & $h=0$ & $h=1 / 3$ & $h=2 / 3$ & $h=0$ & $h=1 / 3$ & $h=2 / 3$ \\
\hline$L:\{500,500,500,500\}$ & 500 & 500 & 500 & 375 & 563 & 1125 \\
\hline$M:\{650,500,425,425\}$ & 500 & 650 & 650 & 364 & 546 & 1092 \\
\hline$H:\{800,500,350,350\}$ & 500 & 800 & 800 & 335 & 502 & 1004 \\
\hline
\end{tabular}


Table 2(a) Bid and Earnings Predictions: English Auction (in cents) ${ }^{*}$

\begin{tabular}{|c|c|c|c|c|c|c|}
\hline \multirow[b]{2}{*}{ Value Set } & \multicolumn{2}{|c|}{$h=0$} & \multicolumn{2}{|c|}{$h=1 / 3$} & \multicolumn{2}{|c|}{$h=2 / 3$} \\
\hline & $\underline{\mathrm{Bid}}$ & Earnings & $\underline{\mathrm{Bid}}$ & Earnings & $\underline{\mathrm{Bid}}$ & Earnings \\
\hline$V_{1}=500$ & 500 & 0 & 500 & 167 & 500 & 333 \\
\hline$V_{1}=500$ & 500 & 0 & 500 & 167 & 500 & 333 \\
\hline$V_{1}=500$ & 500 & 0 & 500 & 167 & 500 & 333 \\
\hline$V_{1}=500$ & 500 & 0 & 500 & 167 & 500 & 333 \\
\hline$M$ & & & & & & \\
\hline$V_{1}=650$ & 500 & 150 & 650 & 217 & 650 & 433 \\
\hline$V_{2}=500$ & 499 & 0 & 649 & 217 & 649 & 433 \\
\hline$V_{3}=425$ & 499 & 0 & 649 & 217 & 649 & 433 \\
\hline$V_{3}=425$ & 499 & 0 & 649 & 217 & 649 & 433 \\
\hline$H$ & & & & & & \\
\hline$V_{1}=800$ & 500 & 300 & 800 & 267 & 800 & 533 \\
\hline$V_{2}=500$ & 499 & 0 & 799 & 267 & 799 & 533 \\
\hline$V_{3}=350$ & 499 & 0 & 799 & 267 & 799 & 533 \\
\hline$V_{3}=350$ & 499 & 0 & 799 & 267 & 799 & 533 \\
\hline
\end{tabular}

Table 2(b) Bid and Expected Earnings Predictions: Lotteries (in cents)

\begin{tabular}{|c|c|c|c|c|c|c|}
\hline \multirow[b]{2}{*}{ Value Set } & \multicolumn{2}{|c|}{$h=0$} & \multicolumn{2}{|c|}{$h=1 / 3$} & \multicolumn{2}{|c|}{$h=2 / 3$} \\
\hline & $\underline{B i d}$ & $\begin{array}{l}\text { Expected } \\
\text { Earnings }\end{array}$ & $\underline{B i d}$ & $\begin{array}{l}\text { Expected } \\
\text { Earnings }\end{array}$ & $\underline{\text { Bid }}$ & $\begin{array}{l}\text { Expected } \\
\text { Earnings }\end{array}$ \\
\hline \multicolumn{7}{|l|}{$L$} \\
\hline$V_{1}=500$ & 94 & 31 & 141 & 172 & 282 & 594 \\
\hline$V_{1}=500$ & 94 & 31 & 141 & 172 & 282 & 594 \\
\hline$V_{1}=500$ & 94 & 31 & 141 & 172 & 282 & 594 \\
\hline$V_{1}=500$ & 94 & 31 & 141 & 172 & 282 & 594 \\
\hline \multicolumn{7}{|l|}{$M$} \\
\hline$V_{1}=650$ & 160 & 126 & 240 & 228 & 481 & 533 \\
\hline$V_{2}=500$ & 99 & 37 & 149 & 169 & 297 & 567 \\
\hline$V_{3}=425$ & 52 & 9 & 78 & 165 & 157 & 632 \\
\hline$V_{3}=425$ & 52 & 9 & 78 & 165 & 157 & 632 \\
\hline \multicolumn{7}{|l|}{$H$} \\
\hline$V_{1}=800$ & 195 & 271 & 292 & 341 & 584 & 551 \\
\hline$V_{2}=500$ & 111 & 55 & 166 & 167 & 332 & 503 \\
\hline$V_{3}=350$ & 15 & 1 & 22 & 161 & 44 & 641 \\
\hline$V_{3}=350$ & 15 & 1 & 22 & 161 & 44 & 641 \\
\hline
\end{tabular}


Table 3. Parameter Combinations Yielding Revenues Estimates

\begin{tabular}{|c|c|c|c|}
\hline \multicolumn{4}{|c|}{ English Auction } \\
\hline$\sim \mathcal{v}(L)$ & $\beta_{o}$ & $\beta_{o}+\boldsymbol{e h}$ & $\beta_{o}+e h+e h^{2 / 3}$ \\
\hline$v(M)$ & $\beta_{o}+e v$ & $\beta_{o}+e h+e v+e h v$ & $\beta_{o}+e h+e v+e h v+e h^{2 / 3}+e h^{2 / 3} v$ \\
\hline$v^{H}(H)$ & $\beta_{o}+e v+e v^{H}$ & $\beta_{o}+e h+e v+e v^{H}+e h v+e h v^{H}$ & $\beta_{o}+e h+e v+e h v+e v^{H}+e h^{2 / 3}+e h^{2 / 3} v+e h v^{H}+e h^{2 / 3} v^{H}$ \\
\hline
\end{tabular}

\begin{tabular}{|c|c|c|c|}
\hline \multicolumn{4}{|c|}{$h(h=1 / 3)$} \\
\hline$\sim v(L)$ & $\beta_{o}+\ell$ & $\beta_{o}+\ell+\ell \boldsymbol{h}$ & $\beta_{o}+\ell+\ell h+\ell h^{2 / 3}$ \\
\hline$v(M)$ & $\beta_{o}+\ell+\ell v$ & $\beta_{o}+\ell+\ell h+\ell v+\ell \boldsymbol{h v}$ & $\beta_{o}+\ell+\ell h+\ell v+\ell h v+\ell h^{67}+\ell h^{67} v$ \\
\hline$v^{H}(H)$ & $\beta_{o}+\ell+\ell v+\ell v^{H}$ & $\beta_{o}+\ell+\ell h+\ell v+\ell v^{H}+\ell h v+\ell \boldsymbol{h} \boldsymbol{v}^{H}$ & $\beta_{o}+\ell+\ell h+\ell v+\ell h v+\ell v^{H}+\ell h^{67}+\ell h^{67} v+\ell h v^{H}+\ell h^{67} v^{H}$ \\
\hline
\end{tabular}




\begin{tabular}{|c|c|c|c|c|}
\hline \multicolumn{5}{|c|}{ Table 4. Revenue Estimates } \\
\hline & $\begin{array}{c}\text { (a) } \\
\text { Parameters }\end{array}$ & $\begin{array}{c}\text { (b) } \\
1^{\text {st }} \text { Half }\end{array}$ & $\begin{array}{c}(\mathrm{c}) \\
2^{\text {nd }} \text { Half }\end{array}$ & $\begin{array}{c}(\mathrm{d}) \\
\text { Predicted }\end{array}$ \\
\hline 0.1 & $\beta_{o}$ & $\begin{array}{c}547.04 \\
(0.00)\end{array}$ & $\begin{array}{c}503.31 \\
(0.00)\end{array}$ & 500 \\
\hline 0.2 & $e v$ & $\begin{array}{l}22.93 \\
(0.37)\end{array}$ & $\begin{array}{l}27.20 \\
(0.36)\end{array}$ & 0 \\
\hline 0.3 & $e v^{H}$ & $\begin{array}{l}-3.92 \\
(0.48) \\
\end{array}$ & $\begin{array}{l}59.74 \\
(0.40) \\
\end{array}$ & 0 \\
\hline 0.4 & eh & $\begin{array}{l}10.13 \\
(0.48)\end{array}$ & $\begin{array}{c}4.41 \\
(0.49)\end{array}$ & 0 \\
\hline 0.5 & $e h^{2 / 3}$ & $\begin{array}{c}7.48 \\
(0.48) \\
\end{array}$ & $\begin{array}{r}13.54 \\
(0.47) \\
\end{array}$ & 0 \\
\hline 0.6 & $e h v$ & $\begin{array}{l}46.22 \\
(0.23)\end{array}$ & $\begin{array}{l}69.61 \\
(0.26) \\
\end{array}$ & 150 \\
\hline 0.7 & $e h v^{H}$ & $\begin{array}{l}29.94 \\
(0.16)\end{array}$ & $\begin{array}{c}37.55 \\
(0.18)\end{array}$ & 150 \\
\hline 0.8 & $e h^{2 / 3} v$ & $\begin{array}{l}-55.77 \\
(0.29) \\
\end{array}$ & $\begin{array}{l}-46.81 \\
(0.33) \\
\end{array}$ & 0 \\
\hline 0.9 & $e h^{2 / 3} v^{H}$ & $\begin{array}{l}-55.70 \\
(0.30)\end{array}$ & $\begin{array}{l}-68.74 \\
(0.26)\end{array}$ & 0 \\
\hline
\end{tabular}

\begin{tabular}{|c|c|c|c|c|}
\hline 1.1 & $\ell$ & $\begin{array}{l}784.10^{* *} \\
(100.00)\end{array}$ & $\begin{array}{c}316.76^{* *} \\
(0.98)\end{array}$ & -125 \\
\hline 1.2 & $\ell v$ & $\begin{array}{l}54.96^{*} \\
(0.22)\end{array}$ & $\begin{array}{c}110.60^{*} \\
(0.93)\end{array}$ & -11 \\
\hline 1.3 & $\ell v^{H}$ & $\begin{array}{c}-144.59 \\
(0.03)\end{array}$ & $\begin{array}{c}-160.38 \\
(0.02)\end{array}$ & -29 \\
\hline 1.4 & th & $\begin{array}{l}161.46 \\
(0.19)\end{array}$ & $\begin{array}{c}4^{480.35}{ }^{*} \\
(0.00)\end{array}$ & 188 \\
\hline 1.5 & $\ell h^{2 / 3}$ & $\begin{array}{c}178.70^{* *} \\
(0.17)\end{array}$ & $\begin{array}{l}408.93 \\
(0.01)\end{array}$ & 562 \\
\hline 1.6 & lhv & $\begin{array}{l}147.81 \\
(0.93)\end{array}$ & $\begin{array}{r}-287.688^{* *} \\
(0.00)\end{array}$ & -6 \\
\hline 1.7 & $\ell h v^{H}$ & $\begin{array}{c}-149.75^{*} \\
(0.02)\end{array}$ & $\begin{array}{c}252.34^{* *} \\
(0.99)\end{array}$ & -15 \\
\hline 1.8 & $\ell h^{2 / 3} v$ & $\begin{array}{c}-177.36 \\
(0.04)\end{array}$ & $\begin{array}{c}203.06 \\
(0.93)\end{array}$ & -16 \\
\hline 1.9 & $\ell h^{2 / 3} v^{H}$ & $\begin{array}{l}-28.59 \\
(0.40)\end{array}$ & $\begin{array}{c}-172.18 \\
(0.05)\end{array}$ & -44 \\
\hline & $\begin{array}{l}\chi^{2}(18) \\
\rho \\
\mathrm{N}\end{array}$ & $\begin{array}{c}\mathbf{1 0 8 . 4 0} \\
0.24 \\
360\end{array}$ & $\begin{array}{c}\mathbf{1 1 8 . 3 4} \\
0.14 \\
359\end{array}$ & \\
\hline
\end{tabular}

Numbers in parentheses are $p$ values giving the probability that the estimates could be that far from zero in the predicted direction when the true parameter value is zero.

Bolded entries highlight instances where $p<.05$. Bolded Italicized entries highlight instances where $p<.10$.

${ }^{*}$ indicates deviations from predicted value at a minimum $90 \%$ confidence level.

${ }^{* *}$ indicates deviation from predicted value at a minimum $95 \%$ confidence level. 
Table 5a. Parameter Combinations that Evaluate the Difference Between Lottery Revenues and English Auction Revenues, and Predicted Values

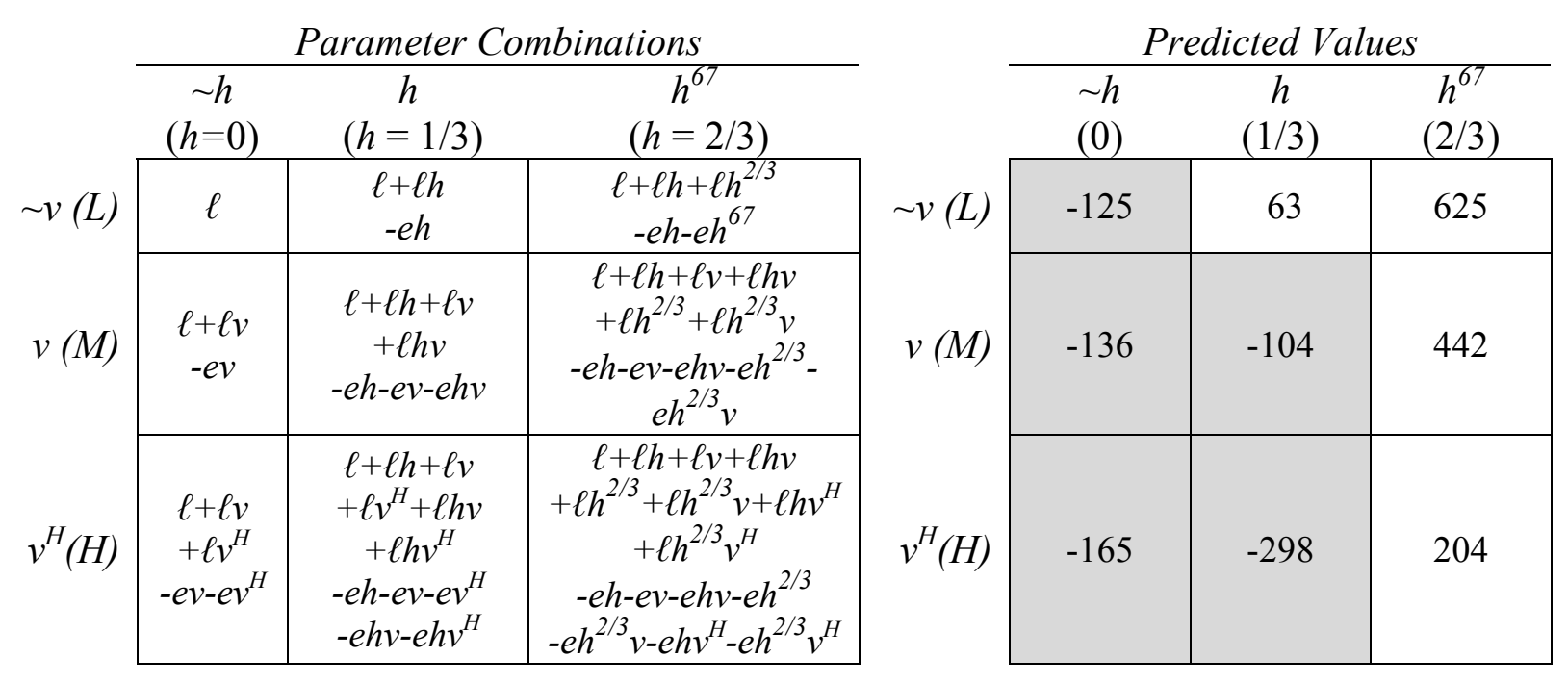

Table 5b. Observed Differences in Lottery and English Auction Revenues

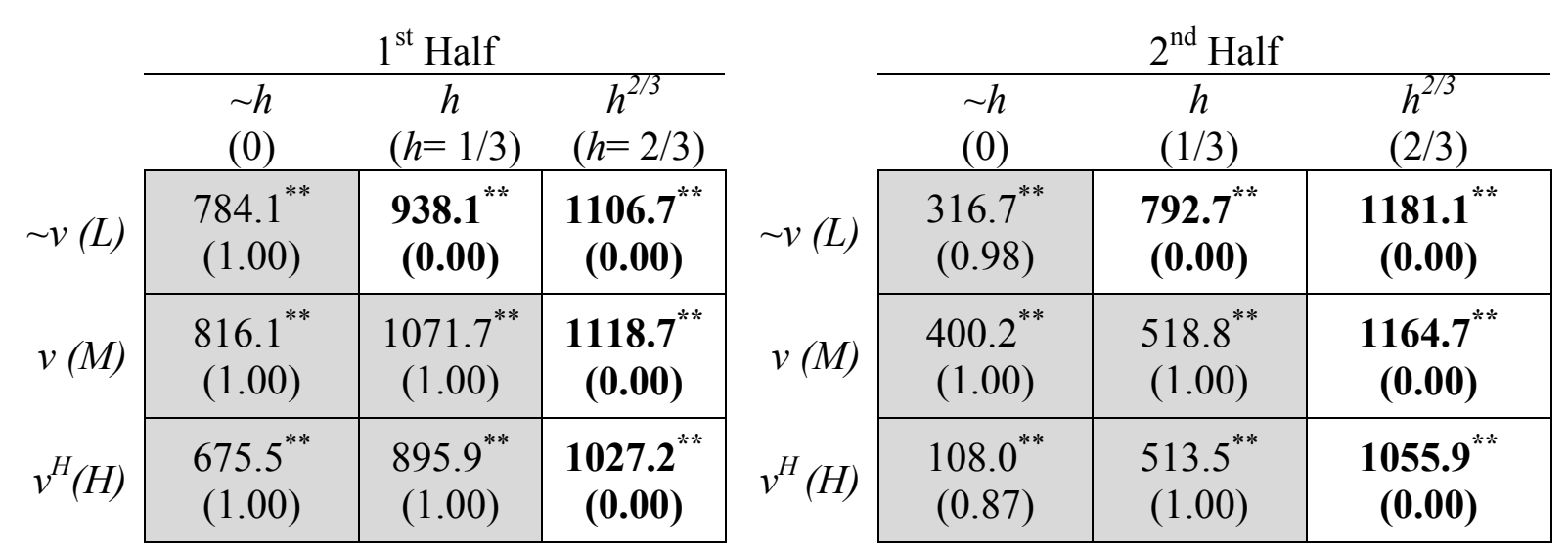

Numbers in parentheses are $p$ values giving the probability that the estimates could be that far from zero in the predicted direction when the true parameter value is zero.

Bolded entries highlight instances where $p<.05$. Bolded Italicized entries highlight instances where $p<.10$.

${ }^{*}$ indicates deviations from predicted value at a minimum $90 \%$ confidence level.

${ }^{* *}$ indicates deviation from predicted value at a minimum $95 \%$ confidence level. 
Table 6a. Parameter Combinations to Evaluate the Effects of Value Set Heterogeneity on English Auction Revenues, and Predicted Values

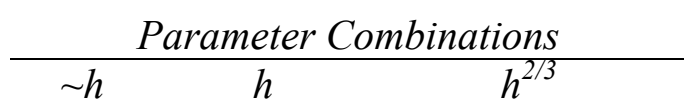

(0)

$v$ less $\sim v$

$(M$ less $L)$

$v^{H}$ less $v$

( $H$ less $M$ )

\begin{tabular}{|l|l|}
\hline \multicolumn{1}{|c}{$(1 / 3)$} & $(2 / 3)$ \\
\hline$e v+e h v$ & $e v+e h v+e h^{2 / 3} v$ \\
\hline$e v^{H}+e h v^{H}$ & $\begin{array}{l}e h^{2 / 3}+e h^{2 / 3} v \\
+e h^{2 / 3} v^{H}\end{array}$ \\
\hline
\end{tabular}
$v$ less $\sim v$
( $M$ less $L)$
$v^{H}$ less $v$
( $H$ less $M$ )

$\frac{\text { Predicted Values }}{\sim h \quad h \quad h^{2 / 3}}$

(0)

\begin{tabular}{|c|c|}
\hline$(1 / 3)$ & $(2 / 3)$ \\
\hline 150 & 150 \\
\hline 150 & 150 \\
\hline
\end{tabular}

Table 6b. Observed Effects of Value Set Changes on English Auction Revenues

\begin{tabular}{lcc}
$1^{\text {st }}$ Half \\
\hline$h$ & $h$ & $h^{2 / 3}$
\end{tabular}

(0)

$v$ less $\sim v$

$(M$ less $L)$

$v^{H}$ less $v$

( $\mathrm{H}$ less $\mathrm{M})$

\begin{tabular}{|c|c|}
\hline \multicolumn{1}{c}{$(1 / 3)$} & $(2 / 3)$ \\
\hline 69.15 & 13.38 \\
$(0.18)$ & $(0.43)$ \\
\hline 26.02 & $-29.68^{* *}$ \\
$(0.35)$ & $(0.37)$ \\
\hline
\end{tabular}

$v$ less $\sim v$

$(M$ less $L)$

$v^{H}$ less $v$

(H less $\mathrm{M}$ )

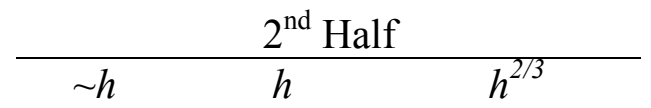

(0)

\begin{tabular}{|c|c|}
\hline \multicolumn{1}{|c}{$(1 / 3)$} & $(2 / 3)$ \\
\hline $\mathbf{9 6 . 8 1}$ & 50.00 \\
$(\mathbf{0 . 1 0 )}$ & $(0.25)$ \\
\hline $\mathbf{9 7 . 2 9}$ & 28.55 \\
$(\mathbf{0 . 1 0 )}$ & $(0.35)$ \\
\hline
\end{tabular}

Numbers in parentheses are $p$ values giving the probability that the estimates could be that far from zero in the predicted direction when the true parameter value is zero.

Bolded entries highlight instances where $p<.05$. Bolded Italicized entries highlight instances where $p<.10$.

${ }^{*}$ indicates deviations from predicted value at a minimum $90 \%$ confidence level.

${ }^{* *}$ indicates deviation from predicted value at a minimum $95 \%$ confidence level. 
Table 7a. Parameter Combinations that Evaluate the Effects of Increasing the MPCR $(h)$ on Lottery Revenues, and Predicted Values

\begin{tabular}{c|c|c|}
\multicolumn{1}{c}{} & \multicolumn{2}{c}{ Parameter Combinations } \\
\cline { 2 - 3 } \multicolumn{1}{c}{} & $\begin{array}{c}h \text { from } \sim h \\
(1 / 3 \text { from } 0)\end{array}$ & $\begin{array}{c}h^{2 / 3} \text { from } h \\
(2 / 3 \text { from } 1 / 3)\end{array}$ \\
\cline { 2 - 3 }$\sim v(L)$ & $\ell h$ & $\ell h^{2 / 3}$ \\
\cline { 2 - 3 }$v(M)$ & $\ell h+\ell h v$ & $\ell h^{2 / 3}+\ell h^{2 / 3} v$ \\
\cline { 2 - 3 }$v^{H}(H)$ & $\ell h+\ell h v$ & $\ell h^{2 / 3}+\ell h^{2 / 3} v$ \\
& $+\ell h v^{H}$ & $+\ell h^{2 / 3} v^{H}$ \\
\cline { 2 - 3 } & &
\end{tabular}

\begin{tabular}{|c|c|c|}
\hline & \multicolumn{2}{|c|}{ Predicted Values } \\
\hline & $\begin{array}{c}h \text { from } \sim h \\
(1 / 3 \text { from } 0)\end{array}$ & $\begin{array}{c}h^{2 / 3} \text { from } h \\
(2 / 3 \text { from } 1 / 3)\end{array}$ \\
\hline$\sim v(L)$ & 188 & 562 \\
\hline$v(M)$ & 182 & 546 \\
\hline$v 1(H)$ & 167 & 502 \\
\hline
\end{tabular}

Table 7b. Observed Effects of MPCR Changes on Lottery Revenues

\begin{tabular}{|c|c|c|}
\hline & & alf \\
\hline & $\begin{array}{l}h \text { from } \sim h \\
(1 / 3 \text { from } 0)\end{array}$ & $\begin{array}{c}h^{2 / 3} \text { from } h \\
(2 / 3 \text { from } 1 / 3)\end{array}$ \\
\hline$\sim v(L)$ & $\begin{array}{c}161.46 \\
(0.39)\end{array}$ & $\begin{array}{c}178.7^{* *} \\
(0.18)\end{array}$ \\
\hline$v(M)$ & $\begin{array}{l}309.27 \\
(0.05) \\
\end{array}$ & $\begin{array}{l}1.34^{* *} \\
(0.50)\end{array}$ \\
\hline$v^{H}(H)$ & $\begin{array}{c}304.11 \\
(0.05)\end{array}$ & $\begin{array}{l}29.93 \\
(0.44)\end{array}$ \\
\hline
\end{tabular}

\begin{tabular}{c|c|c|}
\multicolumn{2}{c}{} & \multicolumn{2}{c}{$2^{\text {nd }}$ Half } \\
\cline { 2 - 3 } \multicolumn{1}{c}{} & $h$ from $\sim h$ & $h^{2 / 3}$ from $h$ \\
$\sim v(L)$ & $(1 / 3$ from 0$)$ & $2 / 3$ from $1 / 3)$ \\
\cline { 2 - 3 } & $\mathbf{4 8 0 . 3 5 *}^{*}$ & $\mathbf{4 0 8 . 9 3}$ \\
\cline { 2 - 3 }$v(M)$ & $(\mathbf{0 . 0 0 )}$ & $\mathbf{( 0 . 0 0 )}$ \\
\cline { 2 - 3 }$v^{H}(H)$ & 192.67 & $\mathbf{6 1 2 . 5 9}$ \\
\cline { 2 - 3 } & $(0.12)$ & $\mathbf{( 0 . 0 0 )}$ \\
\cline { 2 - 3 } & $\mathbf{4 4 5 . 0 1 *}$ & $\mathbf{4 4 0 . 4 1}$ \\
& $(\mathbf{0 . 0 0 )}$ & $\mathbf{( 0 . 0 5 )}$
\end{tabular}

Numbers in parentheses are $p$ values giving the probability that the estimates could be that far from zero in the predicted direction when the true parameter value is zero.

Bolded entries highlight instances where $p<.05$. Bolded Italicized entries highlight instances where $p<.10$.

${ }^{*}$ indicates deviations from predicted value at a minimum $90 \%$ confidence level.

** indicates deviation from predicted value at a minimum $95 \%$ confidence level. 
Table 8a. Parameter Combinations that Evaluate the Effects of MPCR increases on Lottery Revenues Relative to English Auction Revenues, and Predicted Differences

Parameter Combinations $h^{2 / 3}$ from $h$

$(2 / 3$ from $1 / 3)$

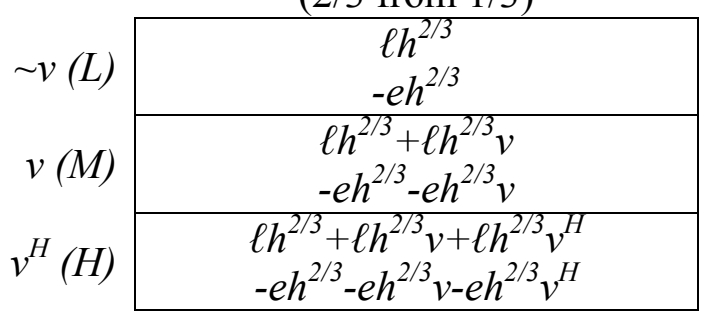

Predicted Difference

$h^{23 /}$ from $h$

$(2 / 3$ from $1 / 3)$

\begin{tabular}{|c|c|}
\cline { 2 - 2 }$v(L)$ & 562 \\
\cline { 2 - 2 }$v(M)$ & 546 \\
\cline { 2 - 2 }$v^{H}(H)$ & 502 \\
\hline
\end{tabular}

Table 8b. Observed Effects of MPCR Increases on Lottery Revenues Relative to English Auction Revenues

\begin{tabular}{cc}
\multicolumn{1}{c}{} & $1^{\text {st }}$ Half \\
\cline { 2 - 2 } & $h^{2 / 3}$ from $h$ \\
& $(2 / 3$ from $1 / 3)$ \\
\cline { 2 - 2 }$v(L)$ & 168.57 \\
& $(0.51)$ \\
\cline { 2 - 2 }$v(M)$ & $46.98^{*}$ \\
& $(0.85)$ \\
\cline { 2 - 2 }$v^{H}(H)$ & $131.27^{*}$ \\
& $(0.37)$ \\
\hline
\end{tabular}

\begin{tabular}{cc}
\multicolumn{1}{c}{} & $2^{\text {nd }}$ Half \\
\cline { 2 - 3 } & $h^{2 / 3}$ from $h$ \\
& $(.2 / 3$ from $1 / 3)$ \\
\cline { 2 - 2 }$v v(L)$ & $\mathbf{3 9 5 . 3 9}$ \\
\cline { 2 - 2 }$v(M)$ & $\mathbf{( 0 . 0 8 )}$ \\
\cline { 2 - 2 }$v^{H}(H)$ & $\mathbf{6 4 5 . 8 6}$ \\
\cline { 2 - 3 } & $\mathbf{( 0 . 0 0 )}$ \\
\cline { 2 - 3 } & $\mathbf{5 4 2 . 4 2}$ \\
& $\mathbf{( 0 . 0 2 )}$ \\
\hline
\end{tabular}

Numbers in parentheses are $p$ values giving the probability that the estimates could be that far from zero in the predicted direction when the true parameter value is zero.

Bolded entries highlight instances where $p<.05$. Bolded Italicized entries highlight instances where $p<.10$.

${ }^{*}$ indicates deviations from predicted value at a minimum $90 \%$ confidence level.

${ }^{* *}$ indicates deviation from predicted value at a minimum $95 \%$ confidence level. 
Table 9a. Parameter Combinations that Evaluate the Effects of Increases in Value Set Heterogeneity on English Auction Revenues Relative to Lottery Revenues, and Predicted Differences.

\begin{tabular}{|c|c|c|c|c|c|c|}
\hline \multicolumn{3}{|c|}{ Parameter Combinations } & & \multicolumn{3}{|c|}{ Predicted Differences } \\
\hline $\begin{array}{l}\sim h \\
(0)\end{array}$ & $\begin{array}{c}h \\
(1 / 3)\end{array}$ & $\begin{array}{c}h^{2 / 3} \\
(2 / 3)\end{array}$ & & $\begin{array}{l}\sim h \\
(0)\end{array}$ & $\begin{array}{c}h \\
(1 / 3)\end{array}$ & $\begin{array}{c}h^{2 / 3} \\
(2 / 3)\end{array}$ \\
\hline & $\begin{array}{l}e v+e h v \\
-\ell v-\ell h v\end{array}$ & $\begin{array}{l}e v+e h v+e h^{2 / 3} v \\
-\ell v-\ell h v-\ell h^{2 / 3} v\end{array}$ & $\begin{array}{r}v \text { less } \sim v \\
(M \text { less } L)\end{array}$ & & 167 & 183 \\
\hline & $\begin{array}{l}e v^{H}+e h v^{H} \\
-\ell v^{H}-h v^{H}\end{array}$ & $\begin{array}{l}e v^{H}+e h v^{H}+e h^{2 / 3} v^{H} \\
-\ell v^{H}-\ell h v^{H}-\ell h^{2 / 3} v^{H}\end{array}$ & $\begin{array}{c}v^{H} \text { less } v \\
(H \operatorname{less} M)\end{array}$ & & 194 & 238 \\
\hline
\end{tabular}

Table 9b. Observed Marginal Differences Between English Auction Revenues and Lottery Revenues as Value Set Heterogeneity Increases t

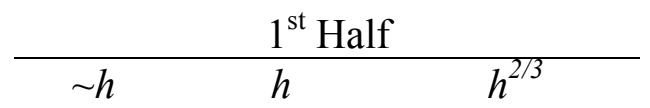

$v$ less $\sim v$

$(M$ less $L)$

$v^{H}$ less $v$

$(H$ less $M)$ vess $\sim v$ $M$ less $L)$ $v^{H}$ less $v$ $(H$ less $M)$

\section{$\frac{\text { Predicted Differences }}{\sim h \quad h^{2 / 3}}$}

$(1 / 3) \quad(2 / 3)$
(0)

$v$ less $\sim v$
$(M$ less $L)$
$v^{H}$ less $v$
$(H$ less $M)$

\begin{tabular}{|c|c|}
\multicolumn{1}{c}{$(1 / 3)$} & $(2 / 3)$ \\
\hline$-133.62^{* *}$ & -12.03 \\
$(0.91)$ & $(0.98)$ \\
\hline $\mathbf{1 7 5 . 7 7}$ & 91.48 \\
$(\mathbf{0 . 0 5})$ & $(0.42)$ \\
\hline
\end{tabular}

$$
\begin{array}{r}
v \text { less } \sim v \\
(M \operatorname{less} L) \\
v^{H} \operatorname{less} v \\
(H \operatorname{less} M)
\end{array}
$$

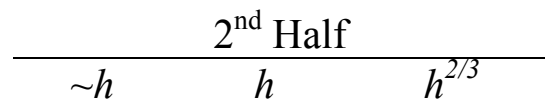

(0)

\begin{tabular}{|c|c|}
\hline \multicolumn{1}{c|}{$(1 / 3)$} & $(2 / 3)$ \\
$\mathbf{2 7 3 . 8 9}$ & 23.42 \\
$(\mathbf{0 . 0 0 )}$ & $(0.15)$ \\
\hline $5.33 *$ & $\mathbf{1 0 8 . 7 7 * *}$ \\
$(0.48)$ & $(\mathbf{0 . 1 0 )}$ \\
\hline
\end{tabular}

Numbers in parentheses are $p$ values giving the probability that the estimates could be that far from zero in the predicted direction when the true parameter value is zero.

Bolded entries highlight instances where $p<.05$. Bolded Italicized entries highlight instances where $p<.10$.

${ }^{*}$ indicates deviations from predicted value at a minimum $90 \%$ confidence level.

${ }^{* *}$ indicates deviation from predicted value at a minimum $95 \%$ confidence level. 


\begin{tabular}{|c|c|c|c|c|c|c|}
\hline \multicolumn{7}{|c|}{ Table 10a. Bid Estimates - High Value Dispersion } \\
\hline \multirow[b]{2}{*}{$\begin{array}{l}\text { Parameter } \\
\quad(p)\end{array}$} & \multicolumn{3}{|c|}{ First Half } & \multicolumn{3}{|c|}{ Second Half } \\
\hline & $h=0$ & $h=1 / 3$ & $h=2 / 3$ & $h=0$ & $h=1 / 3$ & $h=2 / 3$ \\
\hline$\beta_{\mathrm{o}}$ & $\begin{array}{c}380.97 \\
(0.00)\end{array}$ & $\begin{array}{c}461.33 \\
(0.00)\end{array}$ & $\begin{array}{c}516.76 \\
(0.00)\end{array}$ & $\begin{array}{c}443.90 \\
(0.00)\end{array}$ & $\begin{array}{c}448.40 \\
(0.00)\end{array}$ & $\begin{array}{c}435.54 \\
(0.00)\end{array}$ \\
\hline$v^{3}(350)$ & $\begin{array}{l}-63.31 \\
(0.14)\end{array}$ & $\begin{array}{r}-85.09 \\
(0.09)\end{array}$ & $\begin{array}{c}-196.57 \\
(0.00)\end{array}$ & $\begin{array}{c}-226.75 \\
(0.00)\end{array}$ & $\begin{array}{c}-151.88 \\
(0.01)\end{array}$ & $\begin{array}{r}-95.71 \\
(0.05)\end{array}$ \\
\hline$v^{1}(800)$ & $\begin{array}{c}132.89 \\
(0.02)\end{array}$ & $\begin{array}{c}164.31 \\
(0.01)\end{array}$ & $\begin{array}{c}-36.36 \\
(0.28)\end{array}$ & $\begin{array}{c}153.33 \\
(0.01)\end{array}$ & $\begin{array}{c}159.09 \\
(0.00)\end{array}$ & $\begin{array}{c}121.66 \\
(0.03)\end{array}$ \\
\hline$v^{2} \ell$ & $\begin{array}{c}-117.31 \\
(0.07)\end{array}$ & $\begin{array}{l}-67.33 \\
(0.19)\end{array}$ & $\begin{array}{c}-113.56 \\
(0.05)\end{array}$ & $\begin{array}{c}-249.98 \\
(0.00)\end{array}$ & $\begin{array}{l}-77.81 \\
(0.15)\end{array}$ & $\begin{array}{c}6.85 \\
(0.46)\end{array}$ \\
\hline$v^{3} \ell$ & $\begin{array}{c}-87.26 \\
(0.08)\end{array}$ & $\begin{array}{r}-85.09 \\
(0.11)\end{array}$ & $\begin{array}{r}-36.18 \\
(0.24)\end{array}$ & $\begin{array}{c}-84.80 \\
(0.06)\end{array}$ & $\begin{array}{c}-139.40 \\
(0.01)\end{array}$ & $\begin{array}{c}-43.20 \\
(0.25)\end{array}$ \\
\hline$v^{1} \ell$ & $\begin{array}{l}-5.37 \\
(0.47)\end{array}$ & $\begin{array}{c}-103.72 \\
(0.09)\end{array}$ & $\begin{array}{l}61.99 \\
(0.18)\end{array}$ & $\begin{array}{c}-297.88 \\
(0.00)\end{array}$ & $\begin{array}{c}-69.48 \\
(0.17)\end{array}$ & $\begin{array}{l}72.57 \\
(0.17)\end{array}$ \\
\hline$\chi^{2}(6)$ & 40.75 & 32.42 & 41.16 & 80.06 & 87.57 & 52.91 \\
\hline$\rho$ & 0.09 & 0.08 & -0.01 & 0.25 & 0.11 & 0.13 \\
\hline$N$ & 160 & 160 & 160 & 160 & 160 & 160 \\
\hline
\end{tabular}

Numbers in parentheses are $p$ values giving the probability that the estimates could be that far from zero in the predicted direction when the true parameter value is zero.

Bolded entries highlight instances where $p<.05$. Bolded Italicized entries highlight instances where $p<.10$. 


\begin{tabular}{|c|c|c|c|c|c|c|}
\hline \multirow[b]{2}{*}{$\begin{array}{l}\text { Parameter } \\
\quad(p)\end{array}$} & & First Half & & & econd $\mathrm{Ha}$ & \\
\hline & $h=0$ & $h=.1 / 3$ & $h=2 / 3$ & $h=0$ & $h=1 / 3$ & $h=2 / 3$ \\
\hline$\beta_{\mathrm{o}}$ & $\begin{array}{c}446.10 \\
(0.00)\end{array}$ & $\begin{array}{c}526.56 \\
(0.00)\end{array}$ & $\begin{array}{c}401.29 \\
(0.00)\end{array}$ & $\begin{array}{c}408.39 \\
(0.00)\end{array}$ & $\begin{array}{c}460.73 \\
(0.00)\end{array}$ & $\begin{array}{c}397.16 \\
(0.00)\end{array}$ \\
\hline$v^{3}(425)$ & $\begin{array}{c}-182.55 \\
(0.00)\end{array}$ & $\begin{array}{c}-164.40 \\
(0.00)\end{array}$ & $\begin{array}{c}14.09 \\
(0.38)\end{array}$ & $\begin{array}{c}-151.03 \\
(0.00)\end{array}$ & $\begin{array}{l}-20.87 \\
(0.21)\end{array}$ & $\begin{array}{r}-72.85 \\
(0.10)\end{array}$ \\
\hline$v^{1}(650)$ & $\begin{array}{l}69.40 \\
(0.12)\end{array}$ & $\begin{array}{l}31.32 \\
(0.32)\end{array}$ & $\begin{array}{c}156.86 \\
(0.00)\end{array}$ & $\begin{array}{c}125.04 \\
(0.01)\end{array}$ & $\begin{array}{c}114.92 \\
(0.02)\end{array}$ & $\begin{array}{c}167.69 \\
(0.01)\end{array}$ \\
\hline$v^{2} \ell$ & $\begin{array}{l}-39.20 \\
(0.29)\end{array}$ & $\begin{array}{l}-20.16 \\
(0.39)\end{array}$ & $\begin{array}{l}59.21 \\
(0.18)\end{array}$ & $\begin{array}{c}-\mathbf{1 7 7 . 7 0} \\
(0.00)\end{array}$ & $\begin{array}{c}-149.85 \\
(0.01)\end{array}$ & $\begin{array}{l}70.35 \\
(0.18)\end{array}$ \\
\hline$v^{3} \ell$ & $\begin{array}{l}18.27 \\
(0.38)\end{array}$ & $\begin{array}{c}6.35 \\
(0.45)\end{array}$ & $\begin{array}{r}-43.61 \\
(0.20)\end{array}$ & $\begin{array}{l}-47.29 \\
(0.17)\end{array}$ & $\begin{array}{c}-200.55 \\
(0.00)\end{array}$ & $\begin{array}{l}50.93 \\
(0.20)\end{array}$ \\
\hline$v^{1} \ell$ & $\begin{array}{l}-80.65 \\
(0.13)\end{array}$ & $\begin{array}{r}-78.12 \\
(0.12)\end{array}$ & $\begin{array}{r}-31.32 \\
(0.31)\end{array}$ & $\begin{array}{c}-241.21 \\
(0.00)\end{array}$ & $\begin{array}{c}-239.29 \\
(0.00)\end{array}$ & $\begin{array}{l}-40.53 \\
(0.27)\end{array}$ \\
\hline$\chi^{2}(6)$ & 37.11 & 22.90 & 26.05 & 52.02 & 32.05 & 26.05 \\
\hline$\rho$ & 0.13 & 0.04 & 0.04 & 0.04 & 0.08 & 0.04 \\
\hline$N$ & 160 & 160 & 160 & 160 & 160 & 160 \\
\hline
\end{tabular}

Numbers in parentheses are $p$ values giving the probability that the estimates could be that far from zero in the predicted direction when the true parameter value is zero.

Bolded entries highlight instances where $p<.05$. Bolded Italicized entries highlight instances where $p<.10$. 


\begin{tabular}{|c|c|c|c|c|c|c|}
\hline \multicolumn{7}{|c|}{ Table 10c. Bid Estimates - Low Value Dispersion } \\
\hline & \multicolumn{3}{|c|}{ First Half } & \multicolumn{3}{|c|}{ Second Half } \\
\hline & $h=0$ & $h=1 / 3$ & $h=2 / 3$ & $h=0$ & $h=1 / 3$ & $h=2 / 3$ \\
\hline$\beta_{\mathrm{o}}$ & $\begin{array}{c}430.23 \\
(0.00)\end{array}$ & $\begin{array}{c}402.96 \\
(0.00)\end{array}$ & $\begin{array}{c}430.52 \\
(0.00)\end{array}$ & $\begin{array}{c}276.75 \\
(0.00)\end{array}$ & $\begin{array}{c}380.68 \\
(0.00)\end{array}$ & $\begin{array}{c}381.00 \\
(0.00)\end{array}$ \\
\hline $\mathrm{v} 500 \ell$ & $\begin{array}{r}-74.08 \\
(0.06)\end{array}$ & $\begin{array}{l}-30.47 \\
(0.24)\end{array}$ & $\begin{array}{l}-14.84 \\
(0.36)\end{array}$ & $\begin{array}{r}-72.18 \\
(0.09)\end{array}$ & $\begin{array}{l}-58.54 \\
(0.11)\end{array}$ & $\begin{array}{l}44.15 \\
(0.21)\end{array}$ \\
\hline$\chi^{2}(2)$ & 2.60 & 0.49 & 0.09 & 1.81 & 1.55 & 0.60 \\
\hline$\rho$ & 0.18 & 0.05 & 0.11 & 0.05 & -0.07 & 0.04 \\
\hline$N$ & 160 & 160 & 160 & 160 & 160 & 160 \\
\hline
\end{tabular}

Numbers in parentheses are $p$ values giving the probability that the estimates could be that far from zero in the predicted direction when the true parameter value is zero.

Bolded entries highlight instances where $p<.05$. Bolded Italicized entries highlight instances where $p<.10$. 
Table A1 Value Assignments (In Lab Dollars)

\begin{tabular}{clllll} 
& & \multicolumn{4}{c}{ Bidder } \\
Period & Value & $\# 1$ & $\# 2$ & $\# 3$ & $\# 4$ \\
1 & Set & & & & \\
2 & H & 350 & 350 & 500 & $\mathbf{8 0 0}$ \\
3 & M & 500 & 500 & 500 & 500 \\
4 & L & 425 & $\mathbf{6 5 0}$ & 500 & 425 \\
5 & H & 500 & 500 & 500 & 500 \\
6 & M & $\mathbf{8 0 0}$ & 500 & 350 & 350 \\
7 & L & 425 & 425 & $\mathbf{6 5 0}$ & 500 \\
8 & M & 500 & 500 & 500 & 500 \\
9 & H & 350 & 500 & $\mathbf{8 0 0}$ & 350 \\
10 & M & 500 & 425 & 425 & $\mathbf{6 5 0}$ \\
11 & L & 500 & 500 & 500 & 500 \\
12 & H & 350 & $\mathbf{8 0 0}$ & 350 & 500 \\
13 & M & 425 & 500 & 425 & $\mathbf{6 5 0}$ \\
14 & H & $\mathbf{8 0 0}$ & 350 & 500 & 350 \\
15 & L & 500 & 500 & 500 & 500 \\
16 & H & 500 & 350 & $\mathbf{8 0 0}$ & 350 \\
17 & M & 500 & $\mathbf{6 5 0}$ & 425 & 425 \\
18 & L & 500 & 500 & 500 & 500 \\
19 & M & 425 & 425 & $\mathbf{6 5 0}$ & 500 \\
20 & L & 500 & 500 & 500 & 500 \\
21 & H & 500 & 350 & 350 & $\mathbf{8 0 0}$ \\
22 & L & 500 & 500 & 500 & 500 \\
23 & H & 350 & $\mathbf{8 0 0}$ & 350 & 500 \\
24 & M & $\mathbf{6 5 0}$ & 500 & 425 & 425
\end{tabular}



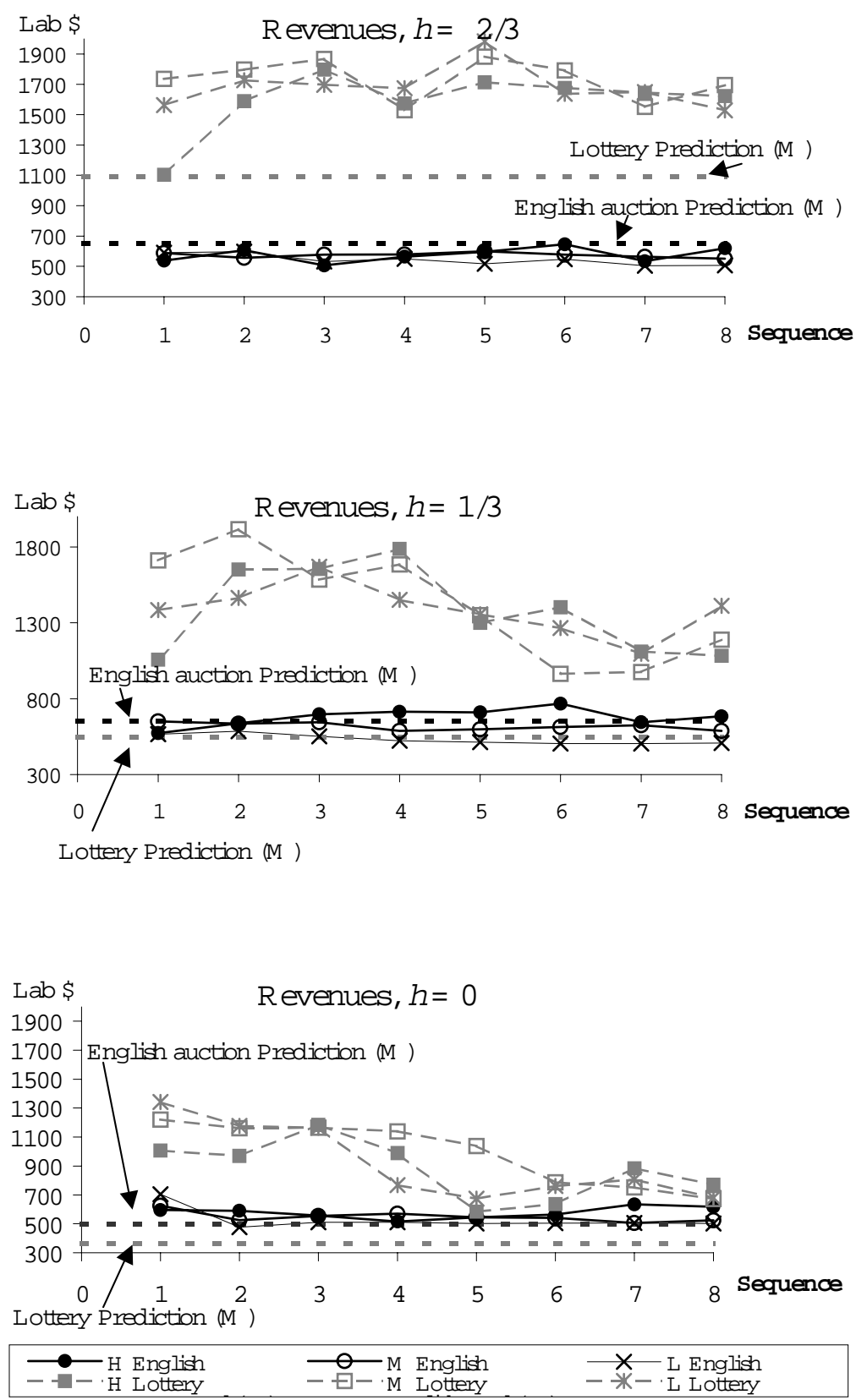

Figure 1. English Auction and Lottery Revenues. Key: Each panel illustrates mean revenues for the 5 sessions in each $M P C R$ condition $(h=0,1 / 3,2 / 3)$. English Auction and lottery observations are separated into sets of 8 sequences conducted under the $H, M$ and $L$ value dispersions. For clarity English auction and lottery predictions are printed for only the $M$ value set. 


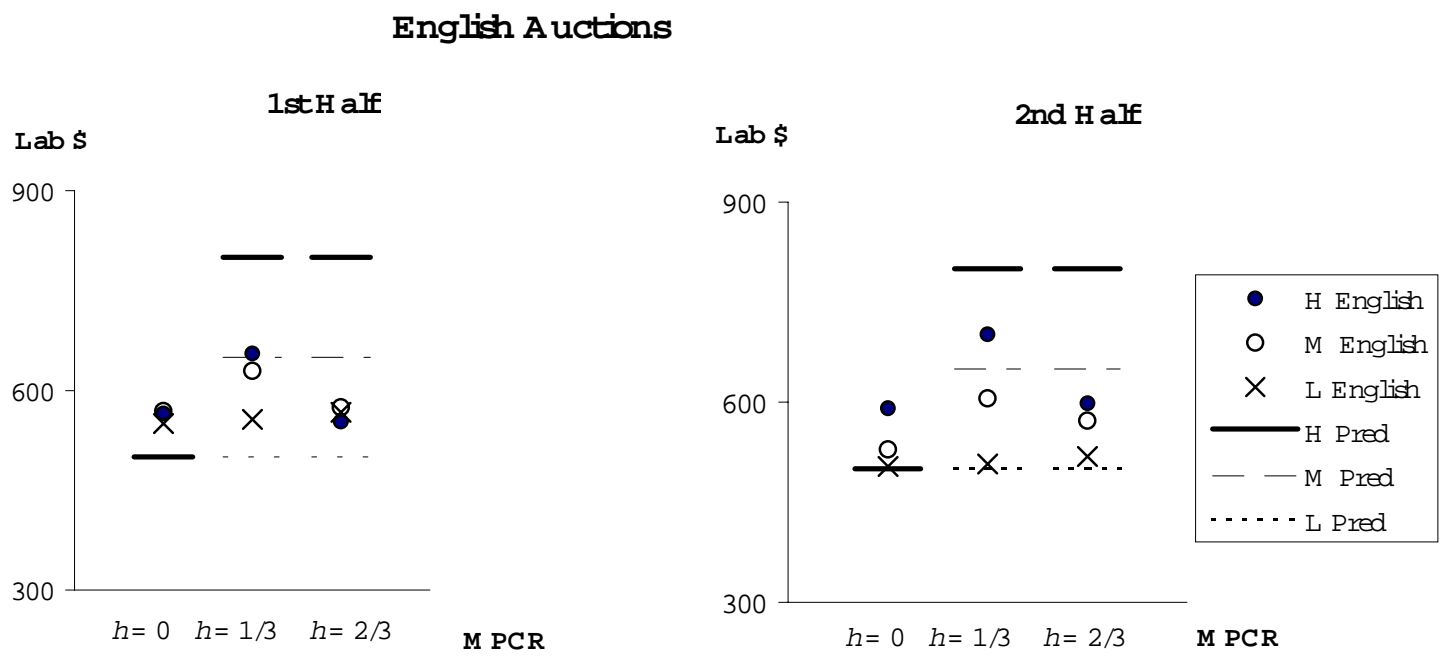

Lotteries
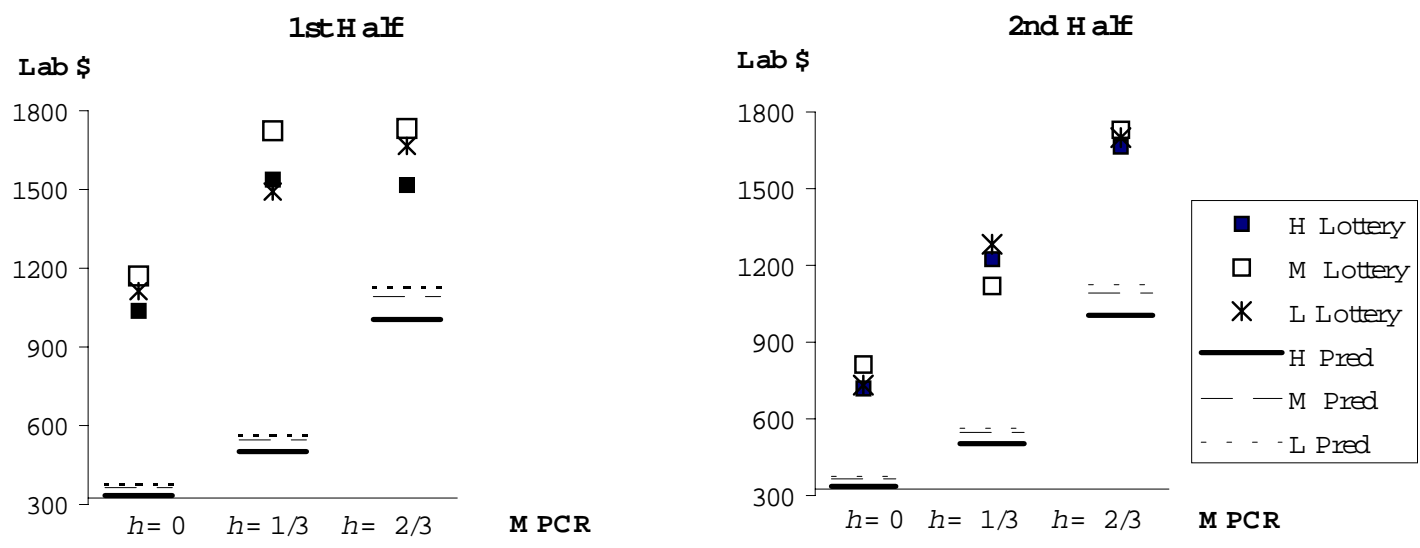

Figure 2. Observed and Predicted Revenues by Session Half. Key: Each Panel Plots Mean Revenues for the First or Second Half of Sessions in a Treatment against Static Nash Prediction. Within panels, markers identify revenues by MPCR $(h=0,1 / 3,2 / 3)$ and by Value Dispersion $(H, M$ or $L)$. 
$H$ igh $\mathrm{V}$ alue $\mathrm{D}$ ispersion
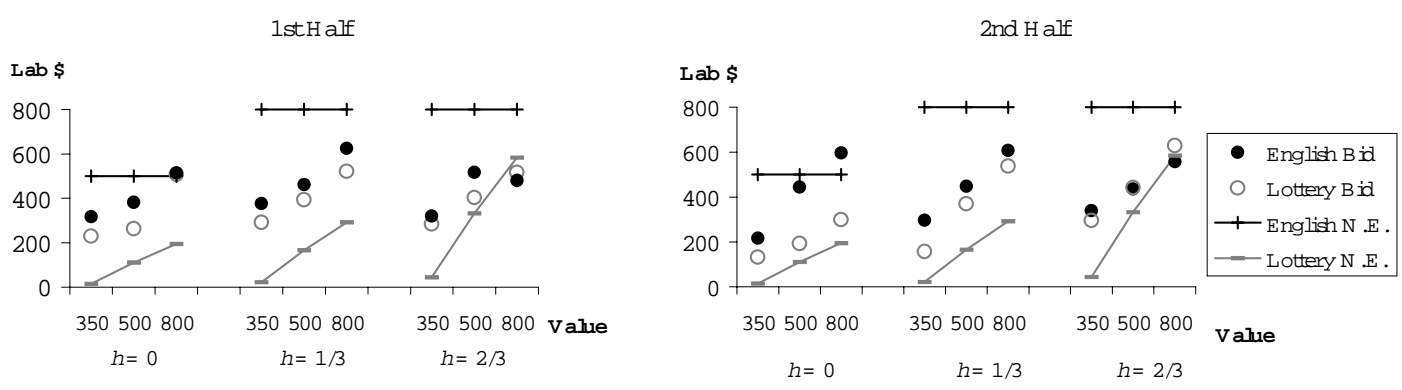

$M$ edium Value $D$ ispersion
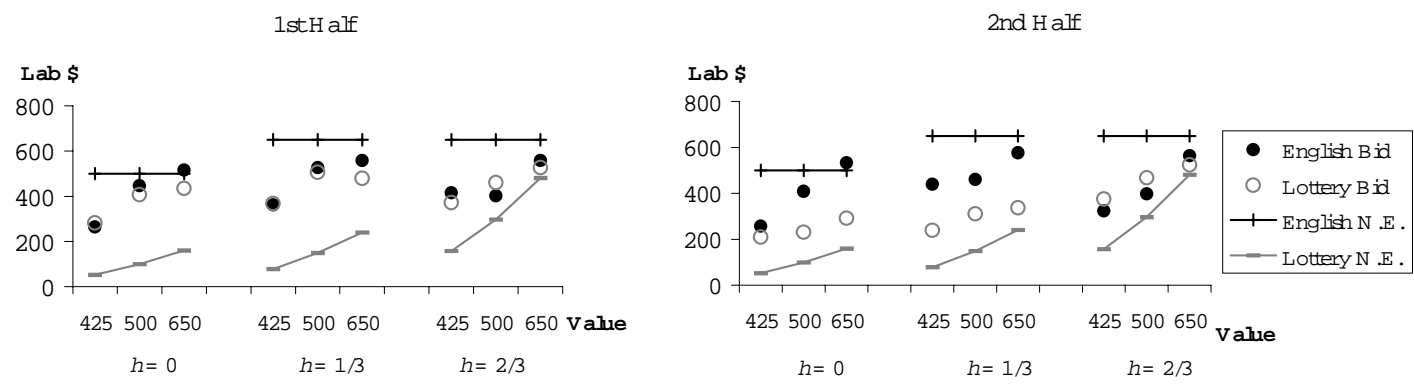

Low Vahe $D$ ispersion
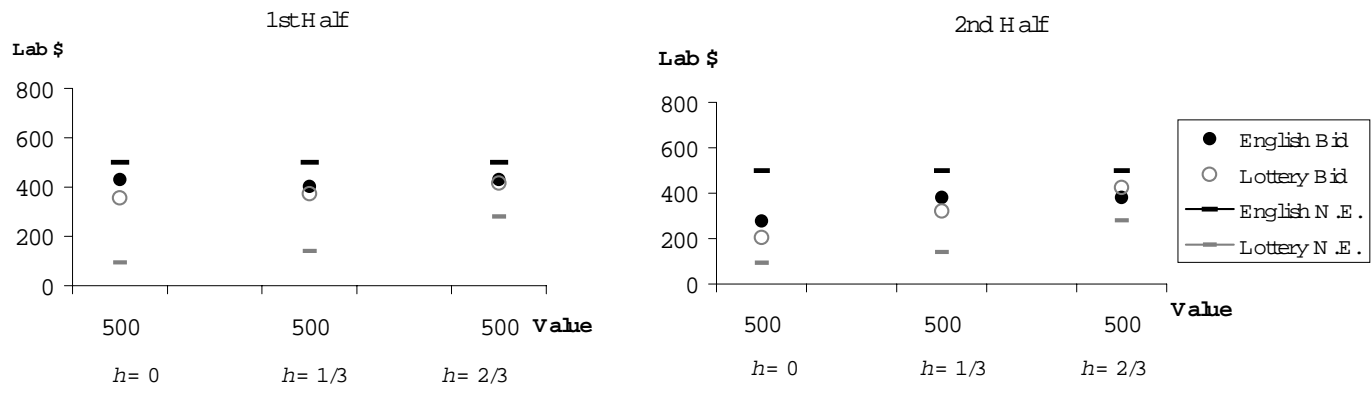

Figure 3. Observed and Predicted Bids by Session Half. Key: Each Panel Plots Mean Closing English Auction and Lottery Bids for the First or Second Half of Sessions in a Value Dispersion Condition. Within panels, markers identify bids by MPCR $(h=0,1 / 3,2 / 3)$ and by Auction Type (English Auction or Lottery). 